\title{
Dos «coplas del fuego» sefardíes en busca de autor
}

\author{
Elena ROMERO * \\ Instituto de Filología - CSIC, Madrid
}

Los estudiosos en el anchuroso campo de las coplas sefardíes nos encontramos con una frecuencia mayor de la que quisiéramos con textos que la tradición nos hace llegar como anónimos, dejándonos en la incógnita los nombres de sus autores. Con ello se hace tarea penosa cualquier intento de completar una nómina de los muchos copleros que alumbraron sus textos en el mundo sefardí de los Balcanes, así como llegar a conocer cabalmente su respectiva obra poética.

En tal situación -la del anonimato- se encuentran los dos textos de los que aquí me ocupo, que he denominado respectivamente $E l$ incendio de Salónica de 1839 y El incendio de Constantinopla de 1883, y el propósito de este artículo es el de aportar algunos datos para la determinación de la autoría de ambas coplas, así como aducir argumentos para la determinación de la fecha y del lugar de ambos sucesos.

\section{A. EL INCENDIO DE SALÓNICA DE 1839}

El texto nos ha llegado en versión única procedente del manuscrito aljamiado titulado Tefter de cantigas, de Mijael Papo (Belgrado

\footnotetext{
*eromero@filol.csic.es

Sefarad 65 (2005) págs. 127-170

(C) CSIC

ISSN 037-0894
} 
1861) ${ }^{1}$ fols. (110-106)v (sólo en los versos, los rectos en blanco), y lleva por cabecera de los folios: «Endecha ${ }^{2}$ del fuego de Istanbul. Meŝatiha nidpéset miSaloniki veźé lešonah 'a"s a'b» ('La encontré impresa de Salónica y esto es lo que dice en acróstico alefático').

Se trata de una copla hasta ahora inédita de 22 nonetas octo-exasilábicas, cuya rima debería ser $a b a b b c c d d$, pero en las que con relativa frecuencia -como es el caso- la rima $a$ (vs. 1 y 3 ) es blanca; tiene acróstico alefático completo, marcadas las letras acrósticas en cuadrada (en mi edición en negrita).

He aquí su contenido. El incendio, consecuencia de los pecados cometidos por Israel (estrs. 1 y 4), estalla la noche primera de Roš hašaná y la gente huye despavorida (estr. 2), viéndose despojada de las pocas cosas que han podido rescatar (estr. 3). Se narran los estragos del fuego (estrs. 5 y 7-8), que a su paso ha arrasado patios, sinagogas, bienes y tiendas (estr. 8), asistiendo impotentes los judíos a la actuación de los artificieros enviados para desembarazar las calles de escombros (estr. 7). El coplero recuerda la futilidad de los bienes terrenales (estrs. 6 y 9); no queda sino rogar a Dios (estrs. 10, 12-13) y suplicarle que mueva la misericordia del sultán (estr. 11). El fuego ha estallado enfrente del baño (estr. 14), dejando a muchos sin hogar (estrs. 15 y 17) y provocando numerosas víctimas (estr. 16). Se dan gracias a un tal Carmona, probablemente por su ayuda a los afectados (estr. 18). A las desgracias provocadas por el fuego parece sumarse la muerte de alguien importante (estr. 19), que debió de producirse durante los días de la fiesta de Sukot ${ }^{3}$. Finalmente, se recomienda arrepentirse de los pecados (estr. 20), acabando la copla con las habituales frases sobre la pronta venida del mesías (estr. 21) y expresando el ansia de redención para acallar a los no judíos que se burlan y niegan sus esperanzas mesiánicas (estr. 22).

Veamos ya el texto (vid. Glosario al final del artículo).

\footnotetext{
1 Uso fotocopia del Ben Zvi Institute (BZI) de Jerusalén, Ms. 3549.

2 Ante el álef aparece tachada una cof, como si el manuscriba hubiera empezado a escribir las palabras cantiga o copla.

3 Recuérdese que dura ocho días, comenzando el 15 de tišrí; de ser cierta la fecha que luego propongo de 1839 , el primer día de Sukot correspondió aquel año al 23 de septiembre.
} 


\section{A.1. El texto}

1 Abrid ojos y mirad estos castiguerios que mos dan de los cielos por muestros rebellos; el remedio de ellos: hacer tešubá, muestra oración suba a el que es Uno con lloro y ayuno.

2 Buen ${ }^{4}$ negocio tuvimos la noche primera ${ }^{5}$, súpito mos topimos por canpos y careras sin cama y estera con muncha abatición, con lloro y esclamación a el muestro padre que mos apiade.

3 Gueźerá se asetenció con ira y saña, subiendo iya el fuego como la araña; toda la conpaña ${ }^{6}$ en un maullo el corazón se les perdió: lo poco que quitaban todo se lo llevaban ${ }^{7}$.

4 Denpués de tanta haftoná no mos escarmentamos y de el sin'at hinam no mos apartamos; sienpre mos topamos en mal apreto, los males a curutú, sienpre somos harbados por muestros pecados.

5 H]El fuego se abrió como la granada, cortando iba el fuego como la espada; la gente honrada, en mala sehorá, pretos como la pólvora, diǰeron: «Pequimos y al Dio culpimos ${ }^{8} »$.

4 Hay que entender la palabra con sentido irónico.

5 Se refiere a la primera de Roš hašaná o Primero de año, fiesta que se celebra el 1 de tišrí y que en los países de la diáspora dura dos días; el año 1839 el primero de tišrí correspondió al 9 de septiembre.

6 Se refiere a la «conpaña» (comunidad) de Israel, es decir, a los judíos.

7 No se explicita quiénes saqueaban a los judíos de lo poco que lograban librar (quitaban) de las llamas.

${ }^{8}$ Es decir, nos hemos hecho culpables ante Dios; los dos versos se repiten en vs. 8h-i. 
6 Vean lo que es, honbres y atanbién ${ }^{9}$ mujeres: emuná non hay que tener en bienes y haberes; un sol de paderes ${ }^{10}$ todo lo seca, tanbién lo hace "asacá ${ }^{11}$; para sus rebellos no bušcan remedios.

7 Źorbalís ${ }^{12}$ parecían sin haber matanza, los cunbaraĝís ían con apresuranza haćiendo esconbranza lo que ellos querían ${ }^{13}$, y los ĵidiós los vían y por sus pecados se quedan callados.

8 Haŝerot y quehilot, mulques y boticas dientro de seš horas ${ }^{14}$ se hićieron flamicas; muncha gente rica ricos se echaron, probes se alevantaron; dijeron: «Pequimos y al Dio culpimos» ${ }^{15}$.

\footnotetext{
${ }^{9}$ Escrito יאה טאנביין.

${ }^{10}$ Es decir, un incendio. Joseph Nehama, Dictionnaire du Judéo-Espagnol (Madrid 1977) s.v. paréd / paré (y s.v. sol) recoge la expresión «sol de paré», que traduce como 'incendie provoqué, mis intentionnellement', aclarando que 'se dit ironiquement quand on fait allusions à un incendiaire'. Independientemente del matiz de intencionalidad que le adjudica Nehama, lo que sí está claro es que se trata de una expresión metafórica: el calor que desprende el sol es el mismo que despiden las paredes de los edificios en llamas.

${ }^{11}$ Escrito עסקא, pero hb. עיסקא 'ascá, 'iscá 'negocio; transacción comercial' deja sin sentido la frase. Supongo que se trata de un error gráfico por הסקה 'icas ' hasacá 'quemamiento, ignición'.

${ }^{12}$ No se excluye la lectura źorbales; cfr. tc. zorba 'violento, brutal', zorballk 'violencia', zorbalık 'motín, rebelión'.

${ }^{13}$ Parece querer decir que los soldados despejaban (haćian esconbranza) lo que les venía en gana, quizá demoliendo edificios sin control ni criterio. No sé si la no clara acusación a los soldados tiene algo que ver con el saqueo aludido supra (vid. vs. 3h-i y nota 7 supra).

${ }^{14}$ Es decir, en el espacio de seis horas, que debió de ser lo que duró el incendio.

${ }^{15}$ Repetición de vs. 5h-i.
} 
9 Todo este mundo es vanidad y nada, firméza no hay en bienes ni en moradas; una vida arastada estamos llevando y la estamos trabando hasta que mos salve del modo que sabe.

10 Ya no mos quedó rúah para sonportarlo, mas que ta'aniyot y tefilot y a él llamarlo y a él trabarlo ${ }^{16}$ por los meźonot, porque hayom ba'avonot ya non quedó riźa ni menos camiśa.

11 K]Corazón de el mélej en tu mano tienes ${ }^{17}$, veluntad a él dale que mos haga bienes y que mos despene por tu elohut; sálvamos de este galut fuerte y amargo, ten ya muestro cargo.

12 La umá preciada, llena de dolores, llevando van haftoná a paños de colores; a ti damos loores todas las horas y los mis ojos lloran; damos tú pacencia para esta setencia.

13 Muestra veluntad en ti la tenemos, afuera de ti, Dio, otro no conocemos; tú haź a los menos ${ }^{18}$ porque eres yašar; sálvamos de tanto ŝáar, tú que mos reśgates de tantos deśbarates.

\footnotetext{
${ }^{16}$ Debemos entender la expresión trabar a Dios con un sentido parecido al de 'tirarle de la manga', es decir, conseguir que, a fuerza de súplicas, provea de vituallas (las meźonot que siguen) a los sufrientes.

${ }^{17}$ La mano es la de Dios.

${ }^{18}$ No sé si con «los menos» se está refiriendo a los pobres.
} 
14 Noche de Roš hašaná, principio de año, el fuego se abrió enfrente del baño; muncho mal y daño a todos alcanzó por huźur y descanso ${ }^{19}$; por mo'ed y fiesta quedimos sin mesta ${ }^{20}$.

15 Señores y señoras enpezaron a llorar de ver tan fuerte fuego que non había carar; lugar onde morar ya no mos quedó.

¿Qué es este negro fado?, mozas por las plazas, todas van descalzas.

16 'Od abrid ojos y mirad lo del día santo ${ }^{21}$ y bušquemos tešubá por muestros pecados; caśas se arastaron, almas volaron ${ }^{22}$, los cielos se abrieron; si no era de día muncho mal venía ${ }^{23}$.

17 Pensimos de tener mo 'ed con repośo, no tuvimos más que dolor en lugar de goźo. ¡Rahamán, piadośo de muestra alma! ${ }^{24}$ que quedimos sin cama, ni mender ni cubierta, todos en las güertas.

\footnotetext{
${ }^{19}$ Es decir, en lugar de paz y tranquilidad, durante los días de la fiesta tuvieron las desgracias mencionadas en vs. $14 \mathrm{e}-\mathrm{f}$.

${ }^{20}$ Escrito מיסטה; cfr. tc. mest 'tipo de botas ligeras y finas que se usan dentro de un calzado más grueso, apto para la nieve y el barro'; la idea de que la gente se ha quedado descalza se repite en los dos últimos versos de la estrofa siguiente.

${ }^{21}$ Por la mención de la tešubá en el verso siguiente, aquí debe de referirse a Yom Kipur, día de arrepentimiento por los pecados.

${ }^{22}$ Es decir, gentes murieron.

${ }^{23}$ Es decir, si el incendio hubiera estallado de noche aún habría causado mayores estragos.

${ }^{24}$ Entiendo la frase como de invocación a Dios, es decir: Tú, que eres misericordioso, sé compasivo con nosotros, ya que hemos quedado como se dice en los versos siguientes.
} 
18 Ŝadic uno se topó, Carmona su nombre, que viva munchos años con honor y honra, porque non deśhonra a ningún honbre ${ }^{25}$; el Dio non lo deśgonbre ${ }^{26}$, porque es muy bueno, de miŝvot muy lleno.

19 Corbanot y sedacot hagamos, hermanos, en mientres que estamos todos vivos y sanos, porque en medianos fue un señor niftar y no hay que ariftar de muestros pecados ${ }^{27}$ mos voló por las manos.

20 Recodravos y mirad lo que habemos pasado, de los males de Iyob habemos trabado; por muestros pecados demandamos pedrón a el que es muestro señor, que mos dé pacencia para esta setencia.

21 Seamos źojim a días de el mašíah, faces de Elía ${ }^{28}$ que es tu šalíah ${ }^{29}$, seremos maŝlíah a de David el goel ${ }^{30}$, rehmidor de Yisrael, presto en estos días que mos dé alegrías.

\footnotetext{
${ }^{25}$ Delante de la palabra y tachado, parece decir enbre.

${ }^{26}$ Nehama, Dictionnaire, s.v. desgomár, explica 'révoquer d'un poste bien rémunéré et qui conférait du prestige, de la puissance'.

${ }^{27}$ Las frases de vs. $g-h$ no las entiendo y en consecuencia no sé cómo puntuarlas Quizá el coplero esté achacando la muerte de la persona mencionada en v. 19f (vid. A.1. Estudio infra) a un castigo por los pecados de todos.

${ }^{28}$ Es decir, merezcamos ver la cara de Elías; escrito אליאה, hb. אליה.

${ }^{29}$ Recordemos que, según la tradición judía, el profeta Elías es el anunciador de los tiempos mesiánicos.

${ }^{30}$ Es decir, al redentor que desciende de la casa de David.
} 
22 Tešubá hagamos, hermanos, a el muestro padre que mos mande la gueulá y non se detadre y que mos manpare por źejut de los abot,

y que vean las umot que se źeflenean y en todo niegan.

\section{A.2. Estudio}

Como vemos, la copla nos habla de un incendio, que, según los datos de la cabecera, habría tenido lugar en Constantinopla, sin que en el texto se indique la fecha, sino sólo que el fuego se produjo el primer día de Roš hašaná (v. 14a). No deja de sorprender la afirmación del manuscriba de haber tomado el texto de una publicación de Salónica y no de la propia Constantinopla, donde según él tuvo lugar el desastre. El único otro dato histórico que nos proporciona el texto es que las víctimas recibieron ayuda de alguien apellidado Carmona (v. 18b, resaltado en letra cuadrada en el manuscrito), sobre el que volveré más tarde.

Lo primero que puedo determinar en cuanto a la fecha del suceso es que tuvo que producirse antes del año 1861, que es el que figura en la portada del manuscrito; tal debe ser también la fecha en que se pusiera por escrito el texto, ya que la letra parece pertenecer a la mano más antigua de las varias que allí figuran.

El manuscrito no conserva el nombre del autor de la copla, pero puedo aportar algunos datos que, a la espera de otros más concluyentes, apuntan a que saliera de la pluma del coplero salonicense Sa'adí Haleví. Recordemos en primer lugar que éste (Salónica ca. 1818 - 14 enero 1903) ${ }^{31}$ pertenecía a una conocida familia de im-

\footnotetext{
${ }^{31}$ Para la fecha de su muerte me sirvo de la que figura en el artículo que, con motivo del fallecimiento de su padre, publicaron los hijos de Sa 'adí Haleví en La Época 28/1372 (17 tebet $5663 / 16$ enero 1903) págs. 1-4. Vid. también los dos artículos de Itshac S. EMMANUEL, «Emprimerías i Empremidores / Baté defús umadpisim (15121968)» [en hebreo], en Zikhron Saloniki ..., redactor David A. RECANATI, 2 vols. (Tel Aviv 1986 y 1972) vol. II, págs. 230-249: págs. 242-243, donde se da como fecha de su muerte 1902; y «Los Jidios de Salonique» [en hebreo], en Zikhron
} 
presores salonicenses y como tal trabajó toda su vida, datando de 1839-1840 el libro más antiguo que hoy por hoy conocemos editado por él. En 1875 fundó y dirigió el periódico La Época, que perduró hasta 1911 a cargo de sus hijos, Daut, Beŝalel y Sam. A todo ello suma su fama como cantor, coplero y también como recopilador de textos tradicionales.

Para la exposición de mis datos debo retroceder en el tiempo. Cuando redactamos hace años el catálogo bibliográfico de ediciones de coplas ${ }^{32}$, incluíamos en núm. 148 el librito que allí llamábamos Complas del fuego a partir del epígrafe que precede a la copla en una página sin numerar; entonces manejábamos las dos hojas que forman el ejemplar del BZI (L-1878) ${ }^{33}$. Hoy, gracias a los hallazgos bibliográficos de Avner Perez, disponemos de un ejemplar completo, cuyo título en cubierta reza Complas de Purim junto la mueva

Saloniki, red. RECANATI, vol. I, págs. 3-272: págs. 183-184; así como las palabras que Emmanuel le dedica en Guedolé Saloniki ledorotam (Tel Aviv 1936) vol. I, pág. 13. Vid. también Joseph NeHAMA, Histoire des Israélites de Salonique (Thessalonique 1978) vol. VII, págs. 714-721, quien da como fechas de su nacimiento y muerte, respectivamente, 1822 y 26 de diciembre de 1904; y la breve biografía de Moshe ATtiAs, «Ham (hajam) Sa'adí Haleví» [en hebreo], en Salonique:Ville Mère (Jerusalén - Tel Aviv 1967) pág. 257, así como sus datos sobre el famoso coplero en «Hag Purim», también en Salonique:Ville Mère, págs. 161-162, publicado antes en «Pourim à Salonique» [en hebreo], Guinzach Saloniki (Archives Saloniciennes) A [= 1] (agosto 1961) págs. 55-73: págs. 63-64. Las memorias de Sa'adí Haleví las publicó su hijo Sam LEVY en el periódico Acción de Salónica en 1931; vid. asimismo las del propio Sam Levy, «Mes Memoires», Tesoro de los Judios Sefardies núms. 4 (1961) págs. IV-XXVI, 5 (1962) págs. XLIV-LXV, 6 (1963) págs. LII-LXXI, 7 (1964) págs. LXIX-LXXXV, 8 (1965) págs. XLV-LXII y 9 (1966) págs. XLIII-LXXIV, donde hace repetidas alusiones a su padre; y probablemente es el propio Sam LEVY quien escribe el breve articulito anónimo sobre Haleví, «L'Apôtre du séfardisme», en Les Cahiers Séfardis 7/8/9 (20 junio 1947) págs. 215-219, donde las fechas que se dan para nacimiento y muerte de nuestro coplero son 1820 y 1903.

${ }^{32}$ Elena Romero, con la colaboración de Iacob M. HASSÁN y Leonor CARRACEDO, Bibliografía analítica de ediciones de coplas sefardíes, Introducción de Iacob M. HASSÁN [abrev. BAECS] (Madrid 1992).

${ }^{33}$ El único dato del que entonces disponíamos para suponer que el libro saliera de las prensas de Sa 'adí Haleví era el nombre de Abraham Ya'acob Herera, que aparece en el colofón como «mesader y maquiinisto» y del que sabemos que era uno de los tipógrafos de la imprenta de Haleví, según figura en el libro Complas de Purim publicado por nuestro coplero en Salónica en 1883 (BAECS 135). 
cantiga por el fuego, el cual vio la luz en Salónica s.d. (ca. 1890), «en la estamparía del jornal La Época». En el texto de portada (h. 1a, parte superior) leemos:

Complas de Purim.- En mi apreto siempre con el Dio me acudí / y de contino a mi Dio yo lo alabí; / bušcando la buendad siempre cansí y sudí, / caminando este camino fue lo que salví. / Seguro conocéš mi chico nombre Sa'adí / y mi alcuña Haleví ... ${ }^{34}$

Gracias a ese ejemplar completo podemos ahora precisar que el que describíamos en $B A E C S$ núm. 148 estaba huérfano de cubierta, de portada (h. 1a) y de las restantes hs. 2-8, conservando sólo las hs. [9-10] de la edición, que es donde está la copla que nos interesa.

El descubrimiento de Perez viene además a salvar dos errores de $B A E C S$ : el de no habernos dado cuenta de que los núms. 154 (descrito a partir de un ejemplar sin cubierta y manco por el final desde la h. 8 en adelante) y el 157 (del que sólo teníamos la cubierta) corresponden a la misma edición que la mencionada de BAECS núm. 148. ¡Complicada ciencia la de la bibliografía sefardí ante el literal despiece en que con frecuencia nos llegan los libros aljamiados que constituyen nuestras fuentes literarias!

Por ser de interés para mi argumentación, reproduzco parte del texto de cubierta (C) y de portada (P) del librito:

[C/P] A la fin de esta guemará / cada uno con placer verá / que tomí la péndola en mano / por recontar a mi hermano / algo sobre el fuego terible / que fue mucho estremecible. / No tenía ninguna entición / ni me pasó por mientes / de dejar esta membración / a muestros vinientes; / ma por el hatir de mis amigos / yo hincho siempre pligos. / Yo no bušco baraná, / como hiźo Ya 'acob Yoná; /

\footnotetext{
${ }^{34}$ Tal entradilla ya había aparecido en otras publicaciones de nuestro autor, por ejemplo, en la portada de su Conplas muevas de Purim (Salónica 1873) (BAECS 118), donde leemos: «En mi apreto siempre con el Dio me acudí / y de contino a mi Dio yo lo alabí; / bušcando la capaciitá siempre cansí y sudí, / caminando este camino fue lo que salví. / Seguro conocéš mi chico nombre Sa adí y mi alcuña Haleví ...».
} 
siendo yo so hombre que [P: lo] hago sin interés. / Y topáš mi nombre con cien y cicuenta y tres; / [C] mi alcuña si quere saber alguno / la topará en cincuenta y uno.

Sí suman 51 las letras del apellido Haleví (הלוי); pero plantea alguna duda la guematria relativa a su nombre. Éste, completo, era Sa'adí Beŝalel, sumando las letras de Beŝalel (בצלאל) las 153 anunciadas para encontrar el nombre, por lo que no parecen entrar en el cómputo las de $S a$ 'adí (סעד =144), cuya adición nos daría un total de 297. Sin embargo, me resisto a creer que el autor de la edición y/o de la copla fueran ni el padre ni uno de los hijos de Sa'adí, ambos llamados Beŝalel Haleví. Mi resistencia viene suscitada por un dato y una suposición. El primero es que, a la luz de los textos de cubierta y portada aducidos supra, los cuales se expresan en primera persona, resulta evidente que el autor de la copla sobre el fuego allí publicada es Sa'adí Haleví y no otro. En cuanto a la suposición, se basa en la alusión a cierta pugna entre el editor del libro y Ya'acob Yoná, el otro coplero y editor salonicense al que me refiero al ocuparme del segundo texto; ambos, si no coetáneos, ya que Yoná era más joven, sî estuvieron, como luego veremos, en estrecha relación durante algún tiempo. Es casi seguro, pues, que las diferencias surgieran entre Yoná y Sa'adí, y no entre Yoná y el padre o el hijo de Sa'adí: el primero por muerto en 1826, aunque su imprenta siguió funcionando por mano de su viuda y de sus hijos hasta $1839^{35}$; y el segundo por demasiado joven.

La «mueva cantiga por el fuego» incluida en el librito, de cuya autoría ya no podemos dudar, la titulábamos (BAECS 148a) El socorro a los quemados (1890) ${ }^{36}$ y se refiere al gran fuego que asoló Salónica el 4 de septiembre de ese año ${ }^{37}$. El texto lo publicó también

\footnotetext{
35 Vid. EMmanuEL, «Emprimerías», pág. 241.

${ }^{36}$ La publico en mi libro Entre dos fuegos (en preparación), Cap. 7 núm. 40.

${ }^{37}$ De este incendio nos hablan P. RISAL [= Joseph NeHAMA], La Ville convoitée: Salonique ( $8^{a}$ ed., París 1913) págs. 211 y 260, y Salonique, vol. viI, págs. 738-739; EMmANUEL, «Jidios de Salonique», págs. 161-162; Michael MolHo, «Los faubourgos de Salonique a traverso los siecolos / Hašejunot hayehuyidot beSaloniki» [en hebreo], en Zikhron Saloniki, red. ReCANATI, vol. Il, págs. 5-31: págs. 12-23 y 19;
} 
Attias ${ }^{38}$ (en aljamiado y enfrentado a su traducción al hebreo), donde atribuye su autoría (pág. 159) a un «poeta desconocido» ${ }^{39}$.

Pues bien, en la cabecera de esta copla dice Haleví: «Versos sobre el trible fuego del 19 elul 650 [= 9 sept. 1890]. Se canta en el son de "Noche de Roš hašaná precipio de año / el fuego se adrió enfrente el baño"», versos que se corresponden con los 14a-b de la copla que ahora nos ocupa, siendo lo más probable que nuestro coplero remitiera en esa copla de 1890 a la melodía de un texto que él mismo hubiera compuesto y no al escrito por otro. No deja de resultar curioso el que en esa copla de 1890 Haleví indique como íncipit melódico no los versos iniciales de esta otra copla suya anterior, sino los de una estrofa intermedia que ocupan su lugar correcto en el orden alefático.

De ser cierta la autoría propuesta, el incendio al que se refiere la copla que aquí estudiamos debió, pues, de ocurrir en Salónica y no en Constantinopla, ya que Haleví en sus poemas noticieros se ocupa preferentemente de asuntos ocurridos en su localidad; y de hecho no tengo ninguna información sobre un incendio en la capital en años próximos a la fecha del manuscrito $(1861)^{40}$.

Sam LEVY «Mes Memoires», núm. 6, págs. LII-LIII; Yitzchak KeREM, «The Effects of Physical Disasters on the Jewish Community of Salonika in the Nineteenth Century», Scripta Hierosolymitana 35 (1994) págs. 49-61: págs. 51-52; y Rena MolHo, «Jewish Working-Class Neighborhoods Established in Salonika Following the 1890 and 1917 Fires», en The Last Ottoman Century and Beyond: The Jews in Turkey and the Balkans, 1808-1945, ed. Minna Rozen (Tel Aviv 2002) págs. 173194.

${ }^{38}$ Moshe ATTIAS, «Ya'acob Yoná - hamešorer ha 'amamí hanoded beSaloniki / Jacob Jona - Wandering Minstrel of Salonica» [en hebreo], Sefunot 15 (1971-1981: The Book of Greek Jewry, v) págs. 153-202: núm. II (págs. 181-186; A.1 pág. 159).

${ }^{39}$ Attias también usó el mismo ejemplar manco del BZI, que nos ha confundido a todos.

${ }^{40} \mathrm{Al}$ mencionar los incendios en Constantinopla, Abraham Galante, Histoire des Juifs d'Istanbul, 2 vols. (Istanbul 1941-1942) vol. II, págs. 136-143, no recoge ningún fuego de fechas próximas a 1861, dando un salto entre los años 1825 y 1865. Lo mismo sucede en Walter F. WeIKer, Ottomans, Turks and the Jewish Polity: A History of the Jews of Turkey (Lanham - New York - London 1992) pág. 129, quien recoge los mencionados por otros historiadores. 
Y quizás, afinando más, podría tratarse del devastador fuego de 1839, cuando Haleví contaba unos 20 años, y del que nos dicen Michael Molho ${ }^{41}$ e Itshac Emmanuel ${ }^{42}$ que estalló precisamente en Roš hašaná de 5600, es decir, en los días 1-2 de tišrí (= 9-10 sept. 1839), y que el ochenta por ciento de las víctimas fueron judíos, quemándose muchas casas, cuatro sinagogas antiguas y numerosas escuelas.

Si he acertado con autoría y fecha, sería ésta la copla más antigua que conocemos del famoso coplero salonicense. En cuanto al sultán reinante, aludido en v. 11a, se trata de Abdul Mecid (1839-1861), estallando el incendio a las pocas semanas de subir al trono ${ }^{43}$.

Gracias a los conocimientos y a la amabilidad de mi querido amigo Dov Cohen, puedo identificar a la persona a cuya muerte se alude en vs. 19e-f y de la que no había encontrado ningún dato en el libro de Emmanuel sobre las piedras tumbales de Salónica ${ }^{44}$. En la introducción del libro de rabí Yehudá Alcalay Šelom Yerušaláyim (Ofen 5600 [= 1839-1840]) (BAECS 66) ps. 3-4 leemos:

... que de mucho tienpo hayá libí hared ['estaba mi corazón tembloroso'] que esta añada «hara"t "olam ${ }^{45} »$ no va ser buena ... y ansí

\footnotetext{
${ }^{41}$ En su artículo «Los faubourgos», págs. 12-13; se ocupa también de este incendio Isaac R. MOLHO, «La comunidad judía de Salónica en el siglo XIX y poco antes» [en hebreo], Tesoro de los Judíos Sefardies 8 (1965) págs. 17-32: pág. 20. Sobre éste y otros incendios en Salónica vid. también la bibliografía que recojo en notas 84-88.

42 «Jidios de Salonique», págs. 114-115, y Guedolé, vol. I, pág. 13; vid. también WeIKER, Ottomans, pág. 129. Recojo más datos sobre dicho incendio en mi libro Entre dos fuegos, Cap. 5 núm. 28.

${ }^{43}$ Vid. I. R. MOLHO, «Salónica siglo XIX».

${ }^{44}$ Itshac S. Emmanuel, Masebot Saloniki / Precious Stones of the Jews of Salonica [en hebreo], 2 vols. (Jerusalén 1963 y 1968) vol. II, quien no recoge ninguna piedra tumbal de ese año 5600 (1839-1840), saltando de 5559 (1838-1839; núms. 17031705) a 1842 (núm. 1706).

${ }^{45}$ El cómputo de las letras consonantes de הרו"ת harat equivale a 5600 [= 1839 1840]. La expresión que aduce el autor como de nefasto presagio está tomada de Jeremías 20.17: «(verahmah) harat 'olam», frase que la comentarística rabínica interpreta como '(y su matriz [de la madre a la que se alude]) será la de una mujer eternamente preñada, que nunca dará a luz', o tambien como 'en su matriz habrá una
} 
lo dije ... betoj quehilatí ['en mi sinagoga'] día de R"h [Roš hašaná] ... ub'avh"r [hb. uba'avonotenu harabim 'y por nuestros muchos pecados'] no fueron días pocos que ya mos alcanzó la šemu 'á ['noticia'] de la serefá ['incendio'] amarga ašer saraf H' ['que quemó el Señor'] noche de Roš hašaná en civdad y madre de Yisrael, Saloniqui ... No salimos de tišrí, alcancimos segunda mala šemu'á, que se amató la candela de Yisrael ... rabenu ['nuestro rabino'] Mošé Sofer ... ${ }^{46}$.

Queda por dilucidar el motivo que indujo al manuscriba de Belgrado a decir que el incendio se produjera en Constantinopla. La única explicación que se me ocurre es que le confundiera la alusión en el texto a alguien apellidado Carmona, apellido de mayor raigambre en esa ciudad que en Salónica y que se había hecho célebre por toda la diáspora sefardí de los Balcanes tras el crimen de estado cometido en 1826 por orden del sultán Mahmud II en la persona del eminente cortesano Chelebí Bejor Carmona ${ }^{47}$.

En un intento por aclarar tal cuestión, debo aludir a algunos hechos históricos. Nos dice Emmanuel ${ }^{48}$ que, tras el incendio, los gobernantes locales y el sultán dispusieron una importante suma de dinero para ayuda de las víctimas de las tres confesiones que moraban en la ciudad: musulmanes, cristianos y judíos. Sin embargo, según cuentan Emmanuel y Molho (quienes lo toman de las memorias de Moisés Montefiore), estando el Barón en Constantinopla, el 30 de octubre de 1840 , es decir, un año largo después del suceso, se entrevistó con él una embajada de la comunidad de Salónica con el ruego de que

preñez eterna'. Tales palabras aparecen asimismo en el íncipit de un piyut del musaf de Roš hašaná, donde la frase «hayom harat 'olam» se interpreta de forma diferente: 'hoy ha comenzado el mundo'; y de aquí deriva la connotación nefasta de la expresión, ya que si ha comenzado un nuevo mundo es porque se ha destruido el anterior. Puede verse un ejemplo de tal piyut en Isaac LEVY, Antología de liturgia judeo-española, X vols. (Jerusalén 1964-1980) vol. II, núms. 159-161 (págs. 199. 202: melodías; pág. 202: textos hebreo y judeoespañol).

${ }^{46}$ Cohen me indica que a este rabino se le conocía por el nombre de Hatam Sofer.

${ }^{47} \mathrm{Me}$ ocupo de largo de este asunto en mi libro Entre dos fuegos, Cap. 5 núms. 26-27.

${ }^{48}$ En «Jidios de Salonique», págs. 114-115 y nota 27; el asunto figura también en I. R. Molho, «Salónica siglo XIX», pág. 20. 
intercediera ante el sultán Abdul Mecid para que, como se había hecho con los afectados de otras confesiones, también se hiciera efectivo el dinero prometido a las víctimas judías del incendio. De lo que se dice en estr. 11e-f se desprende que en el momento de componerse la copla los judíos aún no habían recibido ninguna ayuda del sultán.

De ser así, el tal Carmona bien pudo ser algún notable de Constantinopla ${ }^{49}$ que mediara, junto con Montefiore, en favor de la comunidad de Salónica. Sin embargo, dado que, según he mencionado, la familia Carmona no recuperó su pleno poderío hasta 1856, es decir, unos 17 años después de la fecha que he fijado para el incendio, me inclino a pensar como lo más probable que el Carmona del texto fuera algún miembro, más o menos próximo de la familia de Constantinopla, que residiera en Salónica ${ }^{50}$.

\footnotetext{
${ }^{49}$ La familia había caído en desgracia desde el mencionado asesinato de Chelebí Bejor Carmona y no se vio plenamente rehabilitada hasta 1856 , en tiempos del sultán Abdul Mecid; vid., por ejemplo, M. FranCO, Essai sur l'Histoire des Israélites de l'Empire Ottoman ... (París 1897) pág. 151. En fecha próxima a la del manuscrito -pero casi una veintena de años después de la fecha del incendio que estudiamos- algunos personajes de tal apellido eran importantes miembros de la comunidad de Constantinopla. El mismo FrANCO, Essai, menciona (pág. 162) a la familia, junto con los Camondo, los Hatem y los Hamón, como una de las grandes de la época en el momento de la ascensión al trono del sultán Abdul Aziz (1861) y cita (pág. 166) en 1862 a un Hiźquiyahu Carmona y a un Davidchón Šapší Oglú (o Davidchón [David] Carmona Efendi), el cual en 1867 figuraba entre los banqueros de una comisión provisional nombrada por el gran rabino Yakir Guerón; en 1869 fue nombrado presidente de la comunidad y ese mismo año formaba parte de los cuarenta miembros que constituían el Consejo de Estado (págs. 173, 180 y 239, respectivamente). Por su parte, Avner LEvI, «Changes in the Leadership of the Main Spanish Communities in the N:neteenth-Century Ottoman Empire» [en hebreo], en The Days of the Crescent: Chapters in the History of the Jews in the Ottoman Empire, ed. Minna Rozen (Tel Aviv 1996) págs. 237-271: pág. 260, dice que David Efendi Carmona, senador desde 1877, era en 1883 presidente de la directiva comunitaria de Constantinopla.

${ }^{50}$ Mencionemos, por ejemplo, que Šemuel Sa 'adí Haleví [Sam Levy] en su libro Flama acendida (Salónica 1922) sobre el incendio que destruyó la ciudad en 1917 alude repetidamente a un «musiú Carmona» (págs. 6ss, 63-66, 71, 73-74) entre los que colaboraron in situ en ayudar a las víctimas del desastre.
} 


\section{B. El incendio de Constantinopla de 1883}

Conozco el texto por las siguientes cuatro versiones:

- A: Versión oral cantada por Rosa Avzaradel (Rodas), recogida (6 dic. 1988) por Susana Weich-Shahak en Ashdod (Israel) ${ }^{51}$.

- B: Versión oral de Esmirna, publicada por Isaac Levy ${ }^{52}$.

- C: Versión oral cantada por Rachel Tarica (Rodas) y recogida por Samuel G. Armistead y Joseph H. Silverman en Los Ángeles (30 junio 1958) ${ }^{53}$.

- D: Versión oral de Regina Hanán (Rodas), recogida por Rachel A. Bortnick en Los Ángeles (1985) y publicada por Moshe Shaul ${ }^{54}$.

La copla consta de nonetas octo-exasilábicas, que, teniendo en cuenta los restos de acróstico alefático que muestran las versiones, quizá en el texto original fueran 22; de ellas, a la versión A le quedan 6; a la B, 4 (mancas las estrs. 2 y 4); y sólo 3 a la C (mancas las estrs. 2 y 3 , de difícil audición la última) y a la $\mathrm{D}$. La versión A presenta acróstico alefático de álef a vav; la $\mathrm{B}$ de álef a dálet; en la $\mathrm{C}$ sólo se conservan las letras álef, dálet y bet; y en la $\mathrm{D}$ las álef, guímel y dálet. En la ejecución cantada, la informante de A repite los vs. $h-i$ de todas las estrofas.

La versión $\mathrm{C}$ es inédita, y la versión A -que como veremos es la mejor conservada- la ha publicado también la propia colectora ${ }^{55}$.

\footnotetext{
${ }^{51}$ NSA Y5673b/33.

${ }^{52}$ En Chants judéo-espagnols, vol. III (Jerusalén 1971) núm. 158 (pág. 120), sin datos sobre el informante ni melodía.

${ }^{53}$ Colección de S. Armistead, I. J. Katz y J. Silverman: Tarica.4/2.

${ }^{54}$ En «Las koplas del fuego», Aki Yerushalayim 23/70 (nov. 2002) págs. 40-42: pág. 40.

${ }^{55}$ En su artículo «La estrofa purímica, molde de coplas sefardíes», Anuario Musical 56 (2001) págs. 203-222: págs. 210-211, con anotación musical (pág. 212); en notas señalo las principales diferencias de audición -sólo las léxicas y no las fonéticas- entre el texto publicado por la colectora y lo que yo misma he escuchado. En mi edición no señalo las eses sonoras por fonética sintáctica ni tengo en cuenta
} 
En el momento de la grabación la informante de A inicia el texto en cuatro ocasiones: la primera vez canta de una tirada desde estr. 1 hasta la mitad del v. 4e; las segunda y tercera se interrumpe para dar explicaciones hacia final del v. 1e y al final de v. 1f, respectivamente; la desesperada y ya frenética colectora consigue una versión sin interrupciones al cuarto intento; es ésta la versión que publico, señalando en nota la única diferencia entre las cuatro realizaciones grabadas. Para facilitar mi argumentación, incluyo aquí además las versiones ya publicadas por Levy (B) y Shaul (D), adecuando su grafía a nuestro sistema de transcripción.

Veamos en primer lugar los textos precedidos de un breve resumen del contenido.

La versión A nos dice que el fuego sucedió cuando sucedió -después me ocuparé de tal cuestión- y el autor parece culpar de tal desgracia a que los judíos han aceptado la ley del Tanzimat -palabra camuflada en la frase «d'aquel źimán»-, habiéndose olvidado además de cumplir las leyes sabáticas y de que la única ley del judío es la Torá (estr. 1). El fuego, que ha bajado del cielo como castigo, no ha dejado sana vivienda judía, quedando todos sin vestidos y sin casas, tirados en medio del campo (estr. 2). El desastre ha afectado tanto a pobres como a ricos y el sultán ha enviado gendarmes para que se ocupen de llevar ayuda a los afectados (estr. 3), amén de donar 5.000 ducados para aliviar a las víctimas, que sin techo están padeciendo del frío y de la lluvia (estr. 4). Se insiste en el castigo divino, mencionándose cómo, alojados en barracones, los judíos han perdido

las traslaciones acentuales provocadas por la acomodación del texto literario a la melodía. Dicha versión A la republicó S. WEICH-SHAHAK en sus artículos «Tipología de canciones tradicionales judeo-españolas: Tres géneros poético-musicales sefardíes», Donaire 6 (Londres, abr. 1996) págs. 85-91: págs. 88a-89a, y «Coplas sefardíes: Enfoque poético-musical», Musicología 16/3 (1993) (Actas del XV Congreso de la Sociedad Internacional de Musicología: Culturas Musicales del Mediterráneo y sus ramificaciones, Madrid / 3-10 / IV / 1992) vol. III, págs. 15971609: págs. 1608-1609; y de la mencionada primera publicación por WEICH-SHAHAK en «Estrofa purímica» la retoma SHAUL, republicándola en «Fuego», págs. 41-42, tras la que ahora denomino D. Véase con ello un ejemplo de lo que puede dar de sí un texto en la enmarañada y repetitiva publicística moderna por parte de algunos de los que remueven el caldero de la literatura sefardí. 
todo gozo y descanso (estr. 5), y se recuerda a los niños que han muerto, incitándose a viejos y a jóvenes a hacer duelo (estr. 6).

Resulta singular la estr. 3 de la versión $\mathrm{C}$-que por desgracia se oye muy mal-, la cual no tiene paralelo en las demás versiones. Según ella, alguien vestido a la última moda se sienta cabe el narrador, lleno de estupor y sin saber qué hacer, ya que su casa se ha quemado. Sobre esta estrofa volveré luego en el Estudio filológico (B.3.1).

\section{B.1. Los textos}

\section{Versión A}

1 Año di sičentos y cuarenta y cuatro fuego in seš di kislev de grado ${ }^{56}$ muy alto, porque tomimos por manto ${ }^{57}$ la ley d'aquel źimán ${ }^{58}$, ulvidimos el šabat

y que la Ley amiga ella mos abriga.

2 Ba'avonot qui esto fue negro empecijo, de los cielos abajó este negro gostijo; no quedó cortijo ande había miźuźá ${ }^{59}$, quedimos sin camiśa, sin techo y sin banco, in medio los campos.

\footnotetext{
${ }^{56}$ WEICH-SHAHAK escribe erróneamente degradó.

${ }^{57} \mathrm{La}$ informante se interrumpe aquí en su segunda realización del texto para explicarle a la colectora lo que se dice en vs. 2e-f siguientes: que el incendio sólo afectó al barrio judío y cuál es el significado de la palabra cortijo, que parece entender como turquismo.

${ }^{58}$ WeICH-SHAHAK ha oído mal, escribiendo tal źimán; en la versión B leemos de tal género (?) y en la $\mathrm{C}$ un más lógico di Tanzimán; vid. lo que al respecto digo infra. La informante se interrumpe aquí en su tercera realización del texto para explicarle a Weich-Shahak lo que se dice en el verso siguiente: que la gente no cumplía con las prescripciones sabáticas.

${ }^{59}$ Forma ésta de aludir a casas judías, que son las que tienen meźuźot en sus puertas.
} 
3 Grande derrucamiento fue para el probe y el rico, el guibir y el eśnav todos a un pico ${ }^{60}$;

el goberno rico el rey sultán Hamid mandó muchos źabit que miren la manćía de la judería.

4 Dádivas mandó el rey, cinco mil ducados, qui miren de arrimediar a todos los quimados; los más ${ }^{61}$, entiźnados ${ }^{62}$, sin tener valor, la luvia y la yilor ${ }^{63}$, en pies, muertos di hambre, ya mos abajó calambre.

5 [H]El Dio ya mos amostró siñal temerośo, fuego dil cielo echó ${ }^{64}$ sin tiner ripośo; piedrimos el goźo y el rahatlic, más y más el quiesatlic;

en las quišlás echados como pečes salados.

6 Vergas di huego ichó el Dio de los cielos, a los chiquiticos quimó como los bermuelos; viejos y mancebos in bajo asentad, los ojicos ${ }^{65}$ atentad ${ }^{66}$ : esto fue negra saña de parir en las montañas ${ }^{67}$.

\footnotetext{
${ }^{60}$ Es decir, todos iguales, todos midiendo lo mismo; en la primera realización del texto parece decir «van a un pico».

${ }^{61}$ Es decir, la mayoría.

${ }^{62}$ Aquí con su sentido obvio de cubiertos de tizne de las cenizas; en las versiones B.4b/C.2c/D.3c un más lógico -a tenor de lo que luego se dice-enteśados / entiśados / intiśados 'tiesos de frío'. En la primera realización del texto la grabación se interrumpe aquí bruscamente, oyéndose sólo la primera sílaba de la palabra.

${ }^{63}$ Es decir, bajo la lluvia y el frío.

${ }^{64}$ WEICH-SHAHAK ha transcrito erróneamente aba jó.

${ }^{65}$ Eso es lo que la informante dice, pero debe tratarse de un error por hifícos, con lo que se completaría el trío generacional iniciado en v. 6 e.

${ }^{66}$ Es decir, prestad atención.

${ }^{67}$ La informante explica que eso de «parir en las montañas» lo hacían las jóvenes que habían perdido el «honor» y se iban a parir al campo para que nadie se enterara de su desliz; a continuación también indica que ésta es una copla que va según el
} 


\section{Versión B}

1 A]En año de sečentos y cuarenta y cuatro fuego cayó en Iźmir de grado muy alto; tomimos por manto la ley de tal género, olvidimos el šabat

y la Ley amiga que nos abriga.

2 Ba'avonot que esto fue negro empecijo ${ }^{68}$, no quedó cortijo qu'en él haiga meźuzá, quedimos sin camiśa, deśnudos y descalzos en medio del campo ${ }^{69}$.

3 Gran derrocamiento fue a probes y ricos, el guebir y el eśnaf todos a un pico; el goberno rico del rey sultán Hamid mandó muncho źabit que miren la mancía de la judería.

4 Dádivas mandó el rey cinco mil ducados que miren de arremediar a los más enteśados; $[\ldots]^{70}$ de la luvia y el yelor ya no mos quedó valor ${ }^{71}$, sin techo y sin banco, en medio del campo ${ }^{72}$.

orden alefático. Sobre ese parto vid. también mi comentario infra (B.2. Estudio histórico).

${ }^{68}$ Faltan a continuación los vs. A.2c-d.

${ }^{69}$ Se repiten estos versos, quizás para subsanar en el canto los perdidos arriba.

${ }^{70}$ Falta un verso.

${ }^{71}$ Los tres últimos versos se corresponden respectivamente con A.4e, A.4g y A.4f.

${ }^{72}$ Versos que se corresponden con A.2h-i. 


\section{Versión C}

1 Años de sečentos y cuarenta y cuatro fuego en seš di kislev en grado muy alto; tomimos por manto la ley di Tanźimán, que bušcaldo muncho mal ${ }^{73}$, in pies muertos de hambre llamarás a sus calambres ${ }^{74}$.

2 Dadifás ${ }^{75}$ mandó el rey, cincu mil ducados, que mirin d'aremediar a todos los quemados, y a los intiśados lombre y callintor, que ya no lis quedó valor ${ }^{76}$.

3 Bastonico tiralí con potente dado, con antojicos mavís mi s'asenta 'l lado; el desmaźalado no sabe lo qué hará, que ya perdió el andar ${ }^{77}$.

${ }^{73}$ El verso no tiene correspondencia en A.

${ }^{74}$ Eso es lo que oigo, pero el verso así formulado resulta incomprensible; los dos últimos se corresponden con A.4h-i.

${ }^{75}$ Tal parece oírse, pero significa dádivas como en A/B.4a y D.3a.

${ }^{76}$ Faltan los dos últimos versos. Aquí se nos dice que el sultán manda, amén de los ducados (v. 2b), que proporcionen lumbre y calor (v. 2f) a las personas yertas ( $\mathrm{v}$. $2 \mathrm{e})$, porque ya no pueden aguantar más (v. $2 \mathrm{~g})$. Interesante reformulación y reajuste tradicional, que en esta versión amplía la orden de ayuda del sultán, justificando la necesidad de la misma por la precaria situación en que se encuentran las víctimas del fuego; eso no es lo que se dice en los versos paralelos de A.4e-g/B.4e-f/ D.3e-g, en donde sólo se está describiendo la situación de los afectados.

${ }^{77}$ Faltan los dos últimos versos. Lo que perdió el protagonista de la estrofa es el piso, la vivienda; vid. NEHAMA, Dictionaire, s.v. andár. Es decir, alguien con un bastón, quizá brillante, pulido (cfr. tc. telâ'lii 'brillante'; vid. mi comentario infra en B.3.1 Estudio filológico: Paralelos), y llevando unas gafas azules (tc. sing. mavi) (v. 3c), se sienta junto al narrador. Sobre variantes del enigmático «con potente dado», que es lo que oigo en v. 3b, vid. también mi comentario infra (B.3.1 Estudio filológico: Paralelos). Como ya he señalado arriba, la estrofa no tiene paralelo en las otras versiones. 


\section{Versión D}

1 A]In el año 1844 fuego cayó in la civdad Iźmir di grado muy alto, no quedó cortijo que haiga miźuźá, quidimos sin camiśa, sin techo y sin banco en medio del campo ${ }^{78}$.

2 Grande derrucamiento fue para el probe y el rico, el guibir y el esnaf todos en un pico; el goberno rico el rey sultán Hamid mandó munchos źabit que miren la manćía de la judería ${ }^{79}$.

3 Dádivas mandó el rey, cinco mil ducados, que miren de aremidiar a todos los quimados; los más, intiśados, en la luvia y in la yelor, non mos quidó la valor ${ }^{80}$, in pies muertos de hambre, mos abajó calambre.

\section{B.2. Estudio histórico}

La copla, que sólo conocemos por versiones orales -aunque, como luego veremos (B.3.2), sí parece haber circulado en versión impresa-, nos ha llegado anónima.

Según hemos visto, narra los desastres de un incendio sucedido en lugar y fecha imprecisos, ya que tales datos no coinciden en las cuatro versiones que conozco. Por lo que respecta al lugar, dos textos lo sitúan explícitamente en Esmirna (B.1c/D.1b), habiendo desplazado tal precisión a la mención del día, ya que los otros dos que sí

\footnotetext{
${ }^{78}$ Los vs. le-i se corresponden con A/B.2e-i.

${ }^{79}$ La estrofa se corresponde con A/B.3.

${ }^{80}$ La estrofa se corresponde con A.4; los vs. 3f-g están permutados en relación con A. $4 \mathrm{f}-\mathrm{g}$.
} 
explicitan el día (A.1c/C.1c) nada dicen del lugar. Sin embargo, tal dato queda salvado en ambas versiones, ya que tanto en A como en $\mathrm{C}$ las respectivas informantes, antes de iniciar el canto, les precisan a sus colectores que el incendio se produjo en Salónica.

Por lo que a la fecha se refiere, en tres textos se dice que el fuego ocurrió (A/C.1a-c: mes, día y año; B.1a-b sólo año) el 6 de kislev de (5)644 (= 5 dic. 1883) -a la hebrea-, y en uno (D.1a, sin mes ni día) en 1844 (=5604-05) -a la cristiana-. Para terminar de completar el ya de por sí confuso cuadro, añadamos otros dos datos al respecto: la informante de A le dice a la colectora: «ma no sé [si] año de seteĉentos», lo que nos daría un imposible 1984, es decir, sólo cuatro años antes de que Weich-Shahak grabara el texto; y Rachel A. Bortnick, la transmisora de la versión $\mathrm{D}$, le deja abierta a Shaul la posibilidad de que el año sea 1644, también imposible.

De todo ello lo único que parece claro es que los informantes -que desde luego no son historiadores ni tienen por qué serlo- emiten de sus bocas precisiones que sólo a los estudiosos nos parecen datos históricos, pero que ellos transmiten -y desde luego sin el malvado propósito de volvernos locos- a tenor de lo que les dicta su memoria o su parecer en el momento de la grabación.

Los editores de las versiones $\mathrm{A}, \mathrm{B}$ y $\mathrm{D}$ han resuelto el conflicto de lugar y fecha cada uno a su manera. En su edición de B, nada induce a Levy a meterse en averiguaciones sobre la fecha, y tengo para mí que si indica Esmirna como origen de la informante lo hace a tenor de lo que explicita su texto. Por su parte, Weich-Shahak, al publicar la versión A -que no indica el lugar-, tampoco deja constancia en su artículo del ya aludido dato que, fuera del texto, le proporciona su informante sobre que el incendio sucedió en Salónica; y en cuanto a la fecha, da por buena (pág. 212) la hebrea de 5644 -año correspondiente a los gregorianos 1883-1884-indicando que el 6 del mes de kislev correspondería a noviembre o diciembre de 1883, sin mayor precisión de mes y día. Y por último Shaul, al publicar la versión $\mathrm{D}$-que no tiene indicación ni de día ni de mes, pero sí de lugar: Esmirna-, se asombra del año 1844 (=5604-05) que figura en su texto expresado a la cristiana, ya que afirma que en tal año no hubo ningún fuego en Esmirna; pero, ignorante del dato omitido por 
Weich-Shahak de que el incendio fuera en Salónica, soluciona su asombro remitiendo al texto publicado por esta colectora y a su data de 1883, afirmando convencido (pág. 42) que ese año sí «uvo efektivamente un grande fuego en Izmir». Confusión de confusiones y todo confusión...

Sin embargo, a pesar de la aludida labilidad de los datos históricos explicitados en las versiones, no podemos dejar de tenerlos en cuenta, y tres de ellos me parecen lo suficientemente sólidos como para poder establecer algunas bases de argumentación; son los siguientes:

1) El incendio sólo pudo producirse en un año hebreo cuya última cifra sea cuatro y ello por mor de la rima en $-t(r) o$ de vs. $1 \mathrm{~b}, 1 \mathrm{~d}$ y $1 \mathrm{e}$.

2) En dos versiones (A y C) se puede deducir una alusión a las leyes liberales de los Tanzimat; así leemos «la ley di Tanźimán» (C.1c) y «la ley d'aquel źimán» (A.1c). Tales leyes se iniciaron con el sultán Abdul Mecid (1839-1861) en 1839 y se mantuvieron durante el reinado de Abdul Aziz (1861-1876).

Y 3) El nombre del sultán reinante debe acabar en -id/-it según la rima de vs. A/B.3f /D.2f; las tres versiones mencionadas hablan de un Hamid, que debemos entender como referido a Abdul Hamid II (1876-1909) y no al primero del mismo nombre (1774-1789), aunque, en principio, no podemos descartar a Abdul Mecid (1839-1861).

A priori, los puntos 2 y 3 parecen contener un contradicción histórica. Conviene recordar al respecto que Abdul Hamid II poco tuvo que ver con los Tanzimat o con cualquier reforma de tipo liberal: si bien a los pocos meses de subir al trono aceptó conceder a su pueblo un régimen constitucional, el primer Parlamento, que se abrió el 23 de diciembre de 1876, sólo estuvo vigente hasta 1878 en que fue cerrado por la fuerza, retornando el sultán al más cerrado absolutismo. Para conjugar, pues, ambos inconciliables datos -las menciones en un mismo texto del Tanzimat (punto 2) y de Abdul Hamid (punto 3), lo cual, amén de improcedente, sería sin duda peligroso en un año como 1883- debemos recurrir a lo que se dice en la primera estrofa de la copla: en ella el autor parece ver en el incendio un merecido castigo por haberse olvidado los judíos de cumplir los preceptos del sábado, pero también por haberse abrigado con gusto 
bajo las leyes del Tanzimat. A la contra, tal aseveración no se habría entendido como «políticamente correcta» en tiempos de Abdul Mecid; y por ende, se pensara lo que se pensara en privado ${ }^{81}$, no me parece posible que nadie se atreviera a manifestar a los cuatro vientos -recordemos que el texto se cantaba- posturas radicalmente opuestas a la política del Estado. Con ello, de paso, eliminamos a Abdul Mecid de nuestra discusión.

Como conclusión de los datos mencionados, estamos ante un incendio que debió suceder en un año hebreo acabado en cuatro -mejor en cuarenta y cuatro- durante el período de absolutismo de Abdul Hamid, es decir, entre 1878 y 1908, fecha esta última de la Revolución de los Jóvenes Turcos y de reposición de la Constitución de 1876; tales años pueden ser: 5644 (1883-1884) -como dice el texto-; 5654 (=1893-1894); y 5664 (=1903-1904). Por lo que se refiere al lugar, el incendio pudo suceder en Salónica -como dicen las informantes de $\mathrm{A}$ y $\mathrm{C}-$, o en Esmirna -como dicen las versiones B y D-, sin que, por lo que luego diré, tampoco podamos descartar Constantinopla.

¿Y qué es lo que nos dicen los historiadores para iluminar a los pobres filólogos? Pues lo que sigue.

Al referirse a los incendios sufridos por la ciudad de Esmirna, ni Abraham Galante ${ }^{82}$ ni Meir Benayahu ${ }^{83}$ ni Eliezer Bashan ${ }^{84}$, aportan ninguna información sobre un incendio correspondiente a ese año hebreo de 5644 (=1883-1884). Pero Galante sí menciona otros dos

\footnotetext{
${ }^{81}$ Dado que las reformas iban encaminadas, entre otras cosas- a establecer una cierta igualdad de derechos y de obligaciones para todos -musulmanes y no musulmanes-, muchos judíos vieron un serio problema en lo que tal igualdad implicaba muy especialmente en relación con el servicio militar obligatorio.

${ }^{82}$ Histoire des Juifs d'Anatolie, I: Les Juifs d'Izmir (Istanbul 1937) págs. 204-207 WEIKER, Ottomans, pág. 129 (y fuentes bibliográficas de nota 64) alude a los mismos incendios que Galante.

${ }^{83}$ En «Haserefot haguuedolot beIźmir ubAdrianópoli», Rešumot n.s. 2 (1946) págs. 144-154.

${ }^{84}$ En «Serefot ur 'idot adamá beIźmir bameot ha17-19 ut ‘udá 'al haašamat yehudim bahaŝatá», Miqqedem uMiyyam 2 (1986) págs. 13-27, quien del período que nos interesa añade dos incendios a los mencionados por Galante que escapan a nuestros parámetros temporales.
} 
allí sucedidos cuyos años hebreos acaban en cuatro: uno del 16 de octubre de 1853, en la víspera de Sukot, es decir, el 14 de tišrí de 5614, que debemos descartar por ser anterior a Abdul Hamid; y otro en septiembre de 1903, es decir, entre el 9 de elul de 5663 y el 9 de tišrí de 5664, que sí debemos tener en cuenta.

Por lo que se refiere a Salónica, tampoco encuentro datos sobre un fuego en el año propuesto ni en Nehama ${ }^{85}$ ni en Emmanuel ${ }^{86}$ ni en Molho ${ }^{87}$ al ocuparse de los sucedidos en esta ciudad ${ }^{88}$.

\footnotetext{
${ }^{85}$ En sus diversas listas de incendios acaecidos en Salónica en La Ville, págs. 211 y 260, y en Salonique, vol. VII, págs. $738-739$ y 747-748; vid. también WEIKER, Ottomans, pág. 129.

${ }^{86}$ En Guedolé, vol. I, pág. 13, y en «Jidios de Salonique», págs. 121-122 y 161162. A pesar de acabar en cuatro, no tengo en cuenta el incendio de 1854 que menciona en su artículo citado, sobre el cual parece reinar una cierta confusión. Se trata del fuego conocido como de Eskilich o Kilkich, por el apellido del griego que lo provocó: el incendio estalló en Salónica en el barrio llamado Malta, antes conocido como Franco Mahalé, haciendo explotar el almacén de un griego traficante en armas y explosivos. Sin embargo, los datos que sobre la fecha proporciona EMMANUEL, «Jidios de Salonique», son confusos: primero (pág. 121) fecha el incendio en 5614 (=1853-54) y pocas líneas después (págs. 121-122) en el 9 de tamuź de 5616 (= 12 julio 1856), fecha que en Guedolé, vol. I, pág. 13 se transforma en 7 de tamuź de 5616 , precisando allí que murieron diez judíos. Vuelve a ocuparse de ese incendio en Maŝebot Saloniki, vol. Il, núms. 1720-****1721 (págs. 814-816), en donde ahora figura como única la fecha de 9 tamuź de 5616 / 12 de julio de 1856, recogiendo cinco lápidas de otros tantos judíos muertos en tal circunstancia. Ante el apoyo de las inscripciones tumbales, debo creer que el incendio sucedió en ese último año y día. No lo ha entendido así KEREM, «Physical Disasters», pág. 51, el cual erróneamente ha desdoblado el incendio en dos: uno en 1854 -dato que toma (pág. 51 nota 6) de Emmanuel, remitiendo, por cierto, al editor del libro Recanati y no al autor del artículo- y otro en 1856, contribuyendo a propalar incendios que historiografía más precisa deberá ir apagando.

${ }^{87}$ En «Los faubourgos», págs. 12-13 y 19. Tampoco dicen nada de un incendio en Salónica en 1883 ni KEREM, «Physical Disasters», págs. 50-53, ni WeIKER, Ottomans, pág. 129.

${ }^{88}$ Sí corresponde a un año hebreo acabado en cuatro el que menciona Michael MolHo en su librito en judeoespañol Contribución a la historia de Salonico (Salónica 5692 [= 1932]) págs. 16-17 bajo el epígrafe «El fuego de los Franceśes», y del que también se ocupa EMmanUEL, «Jidios de Salonique», pág. 138. A narrar este incendio con todo detalle se dedica el librito aljamiado Bejí tamrurim ([Salónica], 1 adar 5634 [= 18 feb. 1874]), publicado por Sa'adí Haleví: el fuego, al parecer intencionado, se produjo en la noche del jueves 25 de šebat de 5634 (= 12 feb. 1874) en casa del notable salonicense Ya'acob Francés y entre las llamas murieron el
} 
En cuanto a Constantinopla, Abraham Galante, quien recoge una larga lista de los incendios ocurridos en diversos barrios de la capital y en aldeas próximas ${ }^{89}$, no menciona ninguno correspondiente al año que fija el texto que estudiamos de $5644(=1883-1884)$, pero sí otros dos hebreos que acaban en cuatro: uno del 17 de mayo de 1874 (=1 siván de 5634), que debemos dejar de lado por ser anterior a Abdul Hamid; y otro de septiembre de 1894, es decir, entre el 30 de ab y el 29 de elul de 5654.

Sólo he encontrado un primer apoyo en Paul Dumont ${ }^{90}$, quien sí menciona un incendio sucedido en Hasköy (Constantinopla) en el año dado a la gregoriana de 1883 , precisando además que se quemaron mil casas y que cinco mil judíos quedaron sin hogar.

Por mi parte puedo añadir varios datos a esa información de Dumont sobre un incendio en 5644. En primer lugar, en las dos coplas que narran el fuego sucedido en el barrio de Arabacilar (Hasköy, Constantinopla) en $1908^{91}$, sus respectivos autores, Yishhac B. Šabetay y Ya'acob Rofé, anotan en las cabeceras de sus textos, respectivamente: «Se canta sobre la yoź de las coplas del fuego de 5644» y «Se canta sobre la yoź del cante del fuego de 5644», y, parodiando el texto que estudiamos, empiezan, también respectiva-

propietario y otros once miembros de su familia y servicio. Sin embargo, no considero que pueda identificarse con éste el incendio que se narra en nuestra copla; en primer lugar habría que corregir tres datos del texto: el ar̃o, suponiendo que en su origen estuviera formulado «sečentos y trenta y cuatro»; el mes, que aquí es šebat y no kislev; y el nombre del sultán de vs. A/B.3f /D.2f, que habría que cambiarlo -estropeando la rima- por el de Abdul Aziz (1861-1876), ya que Abdul Hamid no subió al trono hasta el 31 de agosto de 1876. Pero sobre todo, lo que me hace descartar este incendio es el hecho de que se trata de un desastre particular, que afectó a una sola familia, y no general, como obviamente lo fue el que nos ocupa.

${ }^{89}$ En su libro Histoire des Juifs d'Istanbul, vol. II, págs. 136-143.

${ }^{90}$ En su artículo «Une source pour l'étude des communautés Juives de Turquie: Les Archives de l'Alliance Israélite Universelle», Journal Asiatique 267 (1979) págs. 101-135, de donde lo toma WEIKER, Ottomans, pág. 129.

${ }^{91}$ Tituladas en BAECS, respectivamente, Los daños del fuego de 1908 y El fuego y las lluvias de 1908 (BAECS 194a y 195a); las publico parcialmente en mi libro Entre dos fuegos, Cap. 8 núms. 54-55, ahora llamadas Los daños del fuego de Arabacilar y El fuego y las lluvias de Arabacilar. 
mente: «En año de sečentos / y sesenta y ocho» y «Año de sečentos / y sesenta y ocho» ${ }^{92}$. Ni Šabetay ni Rofé indican dónde sucedió tal incendio, pero lo lógico es pensar que hubiera tenido lugar en Constantinopla.

Sin embargo, la información que resulta concluyente para la fijación de lugar y fecha de nuestro furtivo incendio me la ha hecho llegar el mi siempre salvador en casos de apuro, Dov Cohen, a quien vuelvo a dar mis profundas gracias.

En el periódico de Constantinopla El Tiempo 12/1618 (8 kislev 5644 [= 7 dic. 1883]) pág. 3 apareció la siguiente noticia:

La mano tembla y la péndola se estremece por escribir la terible deśgracia del fuego que se abatió miércoles sobre nuestros hermanos de Haskioy. Todo corazón humano no puede somportar de ver un grande lugar, como una civdad, que de la mañana a la tadre fue trastornado en un montón de ceniźa.

Fue a las horas 3 que salió el fuego de un bacal en Arabagâilar y, ayudado de un viento temerośo, el elemento destruidor se espandió por munchas partes, al grado que todo acudimiento era en vano. Los patrones de caśa y capos de famillas, que en este punto se topaban en charší, sintiendo la deśgracia, corieron por salvar sus moradas y mobillas y la más parte de ellos no pudieron por salvar ni el uno ni el otro ...

El fuego de Haskioy es uno de los más grandes deśastres que hubieron este año en nuestro país ... El fuego ... duró 8 horas ... Se calculan 900 caśas y cuatro quehilot ardidas y 2.000 famillas víctimas del deśastre y todas estas caśas, quitando 6 a 7 de turcos y gregos, todas ellas eran moradas de judiós, donde la más parte pobres ...

\footnotetext{
${ }^{92}$ Versos formulados similarmente son frecuentes en coplas sefardíes noticieras. Así, por ejemplo, en la copla de Sa adí Haleví El socorro a los quemados (BAECS 148a; la publico en Entre dos fuegos, Cap. 7 núm. 40) vs. la-b se dice: «En dieź y mueve elul / šečentos y cicuenta»; y lo mismo sucede con dos coplas de Ya'acob Yoná: La crisis de 1913 (BAECS 217b) v. la: «Añada de setenta y tres y de cuatro mos trujo criśa»; y Robo en el puerto de Salónica (BAECS 189a; la publico en Entre dos fuegos, Cap. 7 núm. 38) vs. 5a-b: «Era en año šečentos / y sesenta y cinco».
} 
Fue a la tadre que se pudieron abrigar algunas famillas en las quehilot y en algunas caśas particulares; ma munchas de ellas quedaron en los campos somportando de la luvia y de la nieve, teniendo la tiera por colcha y el cielo por cubierta. Es en este punto que una mujer le tomó las dolores y parió una criatura ...

Su eminencia el Caimacán Efendi [es decir, el Gran Rabino en funciones], harab Mošé Haleví, ... se fue ayer demañana al Palacio y rogó de su maestad el sultán su grande piadad por las víctimas del fuego. Su maestad, conocido por su corazón piadośo ..., de vista, después de haćer la iradé por apropiar la quišlá de la Kubarhané ${ }^{93}$ de abrigo a las famillas víctimas del fuego, ordenó de formar debajo su alta preśidencia un comité de acudimientos. En mismo tiempo su maestad quis̀o bien haćer ihsán mil liras de su haćienda particular en ayudo a los que somportaron en el fuego.

La información continúa en el número siguiente de El Tiempo 12/1619 (12 kislev 5644 [= 11 dic. 1883]), donde además de mencionar la larga lista de donantes, tanto de Turquía como del extranjero, se precisa el número de las víctimas:

Según lo tuvimos anunciado, son 2.000 famillas víctimas del fuego. De estas famillas, 600 se topan abrigadas en la quišlá de Kumbarhané y otras 600 más o menos en unas caśas grandes y caśas particulares.

El asunto se recoge también en el periódico de Esmirna La Buena Esperanza 10/459 (jueves 14 kislev 5644 [= 13 dic. 1883]) pág. 2, donde se amplían algunos detalles:

Una terible catastrofa echó en miśeria y en robina a más de mil pobres famillas de judiós de la capitala. Un grande fuego se declaró el miércoles pasado [6 kislev, $=5$ dic. (1883)] en Haskioy, en el cuartier de Arabaĝilar. Ayudado como estuvo del fuerte viento que soplaba, destruyó más de mil casas, todas habitadas de pobres judiós ... Su maestad el sultán, informado del desastre ..., no se trababa de mandar a cada punto uno de sus yaveres por que

\footnotetext{
${ }^{93}$ Se refiere a los cuarteles o barracones destinados a los cuerpos de artilleros y zapadores (tc. kumbarahane), sitos en el Cuerno de Oro.
} 
fuera en ayudo ... No contente con esto, su maestad combidó al Palacio a su eminencia el Caimacán Efendi y le hiźo saber que, por horas, él acordó 1.000 liras a los pobres judiós que quedaron sin abrigo ... Él ordenó de formar un comitado de ayudos debajo de su alto patronicio ... No contento con esto, ordenó que de vista los cienes de famillas que se topaban en los campos fueran puestas en la grande caserna de Kubarhané y en los locales de la vieja Escola Mediquería y la Escola Militaria. Las desgraciadas víctimas, en tomando aviso ... no mancaron en aquella hora de sus grande tristeza de adrezar al Dio santo sus rogativas por la prosperidad y el alargamiento de la preciosa vida del sultán Abdul Hamid ... [Según el periódico El Telégrafo de Constantinopla] más de 7.000 almas quedaron sin abrigo, dos mujeres murieron del desespero y quinće criaturas murieron del frío ...

La coincidencia de año, mes y día (6 de kislev de 5644 [= 5 dic. 1883]) entre este incendio y el que reflejan los textos que estudiamos (A, B y C), así como la similitud de las circunstancias descritas tanto en las coplas como en las noticias periodísticas -el frío y las lluvias (A.4g/B.4f, C.2e/D.3e-f), el alojamiento en barracones (A.5h) e incluso el parto en descampado (A.6i) - me permiten afirmar que estamos ante el mismo suceso, y que por tanto el fuego tuvo lugar en Constantinopla, en contra de lo que dicen B y D (Esmirna) y de lo que recuerdan las informantes de A y C (Salónica). Aparte del lugar, la única discordancia entre lo que dicen las noticias de la prensa y nuestras versiones radica en la cantidad del donativo del sultán: 1.000 liras en las noticias periodísticas y «cinco mil ducados» en los textos (A-B.4b/C.2b/D.3b); bien es verdad que en la Buena Esperanza se indica que «por horas» ('por el momento'), lo que deja el portillo abierto para pensar que, ante la magnitud de la catástrofe, el sultán aumentara después su subvención.

De la carencia de datos históricos antes expuesta se deduce algo evidente: que el estudio de los incendios que afectaron a los sefardíes de los Balcanes dista mucho de estar concluido, aunque poco a poco la erudición moderna va aportando nuevos datos a los muy valiosos, pero incompletos, proporcionados por los ya clásicos Franco, Rosanes, Galante, Nehama y Emmanuel. Por ejemplo, no deja de resultar sorprendente que, salvo Dumont -quien además cita el incen- 
dio de pasada, sin precisar en este caso su fuente en los Archivos de la Alianza-, nadie más mencione -o yo no he sabido encontrar quién lo haga- un incendio de la magnitud del que estudiamos ${ }^{94}$.

\section{B.3. Estudio filológico}

Pasemos ahora a examinar otros datos que se desprenden del análisis filológico de las versiones, algunos de los cuales pueden aportar cierta luz sobre la autoría del texto que estudiamos.

\section{B.3.1. Paralelos}

En primer lugar quiero ocuparme de la estr. 3 de la versión $\mathrm{C}$, de la cual aparecen claros paralelos en los dos siguientes textos.

El primero, cantado por Ester Gabri (Bulgaria 1919) ${ }^{95}$, dice así en su única estrofa:

Bastonico gilalí, con potín delgado, entojicos y mavís se l'asenta al lado; el deśmázalado no tiene qué haćer, se topa sin parás, en pies, muerto de hambre, le abaǰa calambre.

\footnotetext{
${ }^{94}$ Como elemento comparativo para poner de relieve su virulencia, digamos que en los once que reseña Galante sucedidos en Constantinopla en el período que nos ocupa y siguiendo los datos que nos proporciona en cuanto a casas quemadas y a judíos (o a personas, sin determinar si fueron judíos o no) que quedaron sin hogar, ninguno sobrepasa al de 1883 en cuanto a daños, siendo los más devastadores los siguientes: Balat, 25 de agosto de 1865 (1.500 personas); Kuzkuncuk, 7 de agosto de 1872 ( 196 casas y 1.740 personas); Balat, finales de marzo de 1896 (160 casas y 800 judíos); Hasköy, 1900 (180 casas y 1.500 personas); y Hasköy, 1905 (126 casas y 1.500 judíos). Al parecer sí le sobrepasó el ya citado de Arabacilar (Hasköy) de 1908 (300 casas y 5.000 personas sin hogar). Fuera del período, el peor fue el de 1911 que quemó 520 casas, afectando a 1.000 familias judías y dejando sin techo a más de 4.500

${ }^{95}$ Proyekto Folklore [abrev. PF] de la Radio-Televisión de Israel, núm. 233/5, grabado en 1985 por Moshe Shaul en el Moadón Bet-Abot de Holón (Israel).
} 
En cuanto al segundo, lo encontramos publicado por M. KoenSarano a partir de una grabación hecha, al parecer, en Jerusalén ${ }^{96}$, encabezando un texto al que no pertenece, el de la copla que titulamos Consejos a un muchacho, el cual consta aquí de tres estrofas ${ }^{97}$, que siguen a la que reproduzco (en nuestro sistema de transcripción):

\footnotetext{
${ }^{96}$ En su libro Vini kantaremos: Koleksión de kantes djudeo-espanyoles (Jerusalén 1993) pág. 32. Por desgracia, la colectora, haciendo gala de una asombrosa falta de respeto no sólo y en particular por sus propios informantes, sino también y en general por la tradición sefardí, de cuya defensa tanto blasona, declara en su introducción sin asomo de rubor lo siguiente (pág. 11): «Komo konsulti una grande kantidad de material eskrito i enrejistrado, me es emposible [i!] de mensionar todas las fuentes ke uzí en manera detaliada». Así que, para despachar el problema recoge (pág. 167) en un totum revolutum los nombres de todos aquellos de cuyos materiales orales y escritos se ha servido. Nos quedamos, pues, sin saber el nombre, origen y fecha de nacimiento del/de la informante, datos que cualquier encuestador serio juzga del máximo interés. ¡Qué le vamos a hacer! Aunque para congratular a mis colegas habré de decirles que no nos afecta en este caso la terrible amenaza que suponen otras palabras de la colectora (loc. cit.): «A las vezes sinti de tener ke azer la rekonstruksión de siertos kantes $(*)$, uzando este material, sovre la baza de mi presedente konosensia de sus ... palavras»; afortunadamente el texto que recojo no está afectado del fatídico asterisco. Pero tampoco puedo afirmar que lo que voy a reproducir sea del todo «kašer», es decir, auténtico y no manipulado, ya que más adelante la misma señora afirma con todo cinismo (pág. 12): «I enfin, si meti adientro de siertos kantes unas kuantas palavras mias personales, se meta esto en kuento del fakto ke todo el ke kanta adjusta al kante una parte de si mizmo», frase con la que nos muestra que se siente autorizada a meter pan y cuchara en la salsa de sus informantes. ¡Dios nos libre de aficionados!

${ }^{97}$ Cinco versiones de la cual se encuentran, por ejemplo, en el PF, las tres primeras recogidas por Moshe Shaul: núm. 9/5, de cinco estrofas, en versión de Suzán Mushkatel (Constantinopla 1911), grabada en Pétah Ticvá en 1978, que comienza «Hijo de chica edad / siente mi dotrino»; núm. 22/7, de 4 estrofas, cantada por hombres y mujeres de Turquía en el Moadón Tsión de Yafo (Israel) en 1978, que comienza «Hermanos mis queridos / sentí esta cantiga»; núms. 39/1 (=401/22) y 161/5, dos versiones de Haná Malah (Salónica 1915), la primera de tres estrofas y la segunda bastante descompuesta, grabadas en Tel Aviv 1978; y núm. 48/12, de dos estrofas (la segunda estropeada), cantada por hombres y mujeres de Bulgaria y recogida en el Moadón Tsión de Bat Yam (Israel) en 1978. Ninguna de ellas presenta la estrofa que figura en la versión de Koen-Sarano, siendo la única conexión de dicha versión con el texto de Consejos a un muchacho los vs. $h-i$, que en el texto publicado por Koen-Sarano se han convertido en un a modo de estribillo que se repite tras todas las estrofas, y que figuran también, por ejemplo y respectivamente, en los vs. 2.h-i y 1 .h-i de las versiones $9 / 5$ y $39 / 1$ del PF mencionadas supra.
} 
Bastunico de geveźlí, el potín delgado, la del ojico maví se l'asenta al lado; el deśmaźalado no sabe lo qué hará, no sabe lo qué dirá; ansí vate a tu hecho y verás provecho.

Ambas estrofas aclaran el significado de la oscura estr. C.3: según ellas sabemos que el bastón es o brillante o de nogal y que además el personaje lleva unos finos botines. Pero lo que sigue sin estar claro es la procedencia de esa estrofa, que en la versión de Gabri es única, sin contexto que la ampare, y en la de Koen-Sarano precede a un texto que no es el suyo; no podemos, por tanto, ni afirmar ni negar que formara parte del original de la copla que estudiamos.

Sin embargo, no deja de ser interesante la cierta similitud de formulaciones que presenta el v. C.2g «que ya no lis quedó valor» con el v. $1 \mathrm{~g}$ de una de las versiones de la copla Consejos a un muchacho que antes (nota 97) he señalado (PF 22/7), la cual dice:

Hermanos mis queridos sentí esta cantiga, la hice con grand'amor y muncha fatiga, como la hurmiga en tiempo de la calor;

ya no me quedó valor de caminar hambiertos probes y gavientos;

tal similitud puede haber contribuido a que nuestra estrofa aparezca pegada a versiones de la copla de moral citada.

\section{B.3.2. Autoría}

De mayor interés son algunas otras muestras literarias que apuntarían a que la copla pudo componerla el famoso coplero salonicense Ya'acob Yoná; pero antes de pasar a exponerlas conviene recordar algunos datos sobre su vida. 
Yoná (Monastir 1847 - Salónica 1922) ${ }^{98}$, fijó su residencia en Salónica hacia 1863 o 1865 , cuando tenía 16 ó 18 años ${ }^{99}$, entrando a trabajar como tipógrafo en la imprenta de Sa 'adí Haleví, en donde, según Emmanuel ${ }^{100}$, sólo trabajó de 1867 a 1868, afirmación que viene corroborada por los siguientes datos: durante esos años salieron de la imprenta de Haleví al menos tres libros en los que se menciona a Yoná como «mesader», a saber, Séfer Me'am lo'eź Yehošúa', vol. I (Salónica 1867), Šir haširim 'im targum veladino (Salónica 1867) ${ }^{101}$ y Séfer Żejut umišor (Salónica 1868); y también trabajó en 1867 como «po'el hadefús» ('obrero de la imprenta') de Guemilut Hasadim para el calendario Hemdat Daniel del año 5628 (1867). Pero, soprepasando los límites temporales que indica Emmanuel para su empleo con Sa'adí Haleví, lo encontramos en 1869 trabajando asimismo como tipógrafo de dos libros -Tres complas (1869, vid. BAECS 113) ${ }^{102}$, y el calendario Hemdat Daniel para el año 5630 (= 1869) ${ }^{103}$-, publicados en Salónica por la Estamparía Estabilida, que hay que identificar con la de Haleví ${ }^{104}$.

Sin embargo, según los recuerdos de Rachael Castelete, parece que fueron bastantes más los años que trabajó con Sa'adí Haleví, quizá desde su llegada a Salónica (1863/1865) hasta un tiempo impreciso que debió sobrepasar el año 1869. Durante esos años se casó con la sobrina de Haleví, Dudún Mataraso, y algún tiempo después de la boda se independizó, abandonando la imprenta de su pariente

\footnotetext{
${ }^{98}$ Sobre su vida vid. ATtiAS, «Yoná», págs. 155-157; y especialmente Samuel G. ARmistead y Joseph H. Silverman, The Judeo-Spanish Ballad Chapbooks of Yacob Abraham Yoná (Berkeley - Los Ángeles - London 1971) págs. 3-9. Vid. también Shmuel REFAEL, «R' Ya ‘acob Yoná, mešorer ha 'itim šel Saloniki», Pe ‘amim 70 (1997) págs. 100-123.

${ }^{99}$ Vid. ARmistead y Silverman, Yoná, pág. 5, quienes recogen los datos proporcionados por Rachael Castelete, hija de Yoná.

100 «Empremerías» pág. 243.

101 Vid. BAECS 111.

${ }^{102}$ El nombre aparece al final del librito, que al redactar BAECS manejábamos en un ejemplar manco por el final.

${ }^{103}$ Dato este último que debo a Dov Cohen

${ }^{10+}$ Vid. EMmanUel, «Empremerías», pág. 243 nota 39.
} 
político. De cualquier forma, es casi seguro que su empleo en la empresa de Sa 'adí Haleví no sobrepasara la primera quincena del mes de iyar de 5634 (= entre el 18 de abril y el 2 de mayo del año 1874), mes en el que nuestro impresor fue anatematizado por el rabinato local y los obreros de su imprenta amenazados si proseguían trabajando para él.

La situación la describe el propio Sa 'adí Haleví en su Cómo nació La Época, adelanto de sus memorias que en 1907 publicaron los hijos del ya fallecido impresor, donde al respecto leemos (entrega núm. 8 col. d) ${ }^{105}$ :

[Tras la excomunión] La estamparía estaba cerada, siendo no dejaban a ninguno confiarme laboro y miśmo los componedores habían sido menaźados de mil males si piśaban más por mi caśa ...;

y más adelante (entrega núm. 9 cols. $a-b$ ):

Solamente los laboradores no puedían venir. No por negra veluntad, siendo ellos me eran muy devuados y cas̀i todos más aedados de mí. Yo los había topado a la imprenta en viniendo al mundo y, al enjemplo de mi padre y mi madre, los trataba siempre como hermanos ... Si los laboradores no puedían venir, era por lo que no los dejaban. Ma por esto yo no estaba en pena: yo miśmo [y] mi hijo mayor puedimos componer; las mujeres sabían estampar, doblar y encachar; de modo que la familla sola ya bastaba para haćer los laboros uśuales que no demandaban grande esforzo ni eran presurośos.

Por desgracia, no tenemos hoy por hoy datos que nos permitan seguir con precisión la vida editorial de Yoná desde 1869 -en que como el Guadiana, desaparece- hasta 1890-1891, es decir, más de viente años después de los libros arriba citados en que aún trabajaba para Haleví; desde 1891 lo volvemos a encontrar trabajando en Saló-

105 Uso fotocopia del BZI L-1107-5, ejemplar en el que aparecen encuadernadas las entregas de un folletón, que, sin embargo, por su formato no tienen el aspecto de haberse publicado en el periódico La Época. 
nica ${ }^{106}$ hasta su muerte en 1922. Salvo el breve paréntesis que luego indicaré, no sabemos qué hizo Yoná ni dónde estuvo durante esa veintena de años.

Las muestras literarias a las que antes me refería son las de la semejanza textual entre la copla que estudiamos y la ya aludida de $E l$ fuego grande (1890) (BAECS 151a) ${ }^{107}$, escrita por Yoná para narrar el terrible incendio que tuvo lugar en Salónica el 4 de septiembre de ese año ${ }^{108}$; sus estrs. 13 y 21 dicen, respectivamente:

Muestro rey mandó a dar cinco mil ducados que miren de aremediar a todos los quemados; los más, enteẑados, sin tener valor,

la luvia y la yelor, en chadires echados como peče salados,

paralela de la estr. A/B.4/C.2/D.3 del presente texto; y

Čeremonia pareció a padre y a hijo, al mundo estremeció de este gustijo; non mos quedó cortijo que haiga meźuźá, quedimos sin camiśa, sin techo y sin banco en medio de el campo,

paralela de la estr. A/B.2/D.1.

Aún encontramos otra versión paralela de la citada estr. A/B. 4/C.2/D.3 en la copla escrita también por Yoná con motivo del incendio de Salónica de 1917, que titulo El fuego de 1917 (BAECS 221a) ${ }^{109}$, cuya estr. 13 reza así:

\footnotetext{
${ }^{106}$ Los libros impresos en ese año son: Cantiga por el fuego (Salónica 1891) (BAECS 151), donde se publicó su copla de El fuego grande (1890) a la que luego me referiré; Séfer Guedulat Mošé ([Salónica] 1891) (BAECS 153); y La salud (Salónica 1891).

${ }^{107}$ La publico en Entre dos fuegos, Cap. 7 núm. 41.

${ }^{108}$ De este incendio ya me he ocupado supra (apartado A).

${ }^{109}$ La publico en Entre dos fuegos, Cap. 14 núm. 137.
} 
Mandaron de Londra a dar grande suma de ducados que miren de ayudar a todos los sinistrados; los más, enteẑados, sin tener valor, con luvias en la yelor, en Karaisín y Dudular ${ }^{110}$ echados como pešcados salados.

$\mathrm{Y}$ un eco de la relación que en el texto se establece entre la yelor $\mathrm{y}$ los calambres (A.4 vs. $g$ e $i /$ D. 3 vs. $f$ e $i$ ) lo volvemos a encontrar en otra copla de Yoná, la que titulo La guerra y la miseria de 1912 (BAECS 214a) ${ }^{111}$, en cuyo v. 6b leemos: «y de muncho frío murieron gente, que les abajó calambre».

Nada tiene de sorprendente que para narrar los incendios de 1890 y de 1917 Yoná repitiera formulaciones que ya hubiera empleado en alguna otra ocasión; el que Yoná se copiaba a sí mismo -y también a su pariente político Sa'adí Haleví- es un fenómeno tan conocido de los investigadores que no hace falta insistir en ello. Por poner un mínimo y único ejemplo de lo segundo -sus copias de Haleví- digamos que el inicio de esa estr. 21 de El fuego grande de Yoná que acabo de citar repite una formulación acuñada por Sa 'adí Haleví en 1873 en su copla Los tiempos modernos (BAECS 118e), donde en los dos primeros versos de su estr. 21 leemos: «Čirimonia pareció / por aquella hora» ${ }^{112}$.

Como vemos, en el texto de Yoná sobre el incendio de 1890 (v. 13b) también se indica como donativo del sultán la suma de 5.000 ducados, cifra con la que, por otra parte, también coincide Emmanuel ( $₫ 5.000$ liras turcas»), sin indicar la procedencia de su dato ${ }^{113}$.

\footnotetext{
${ }^{110}$ Nombres de dos lugares próximos a Salónica (el primero Kara Huseyn) donde se montaron tiendas de campaña para dar refugio a los sin techo tras el incendio de 1917.

${ }^{111}$ La publico en Entre dos fuegos, Cap. 11 núm. 99.

${ }^{112}$ En colaboración con Dora Mancheva, preparo un artículo sobre el plagio que de este texto de Haleví hizo Yoná en su copla El lujo y la escasez (BAECS 220a).

113 «Jidios de Salonique», pág. 162. Difiere, sin embargo, lo que al respecto nos dice Sa'adí Haleví en su copla de El socorro a los quemados (1890), a la que me he referido supra (apartado A), en donde leemos: «El sultán se engajó / con mil y quinientos». Tal diferencia entre los dos copleros en la cuantía del donativo induce
} 
A la vista de las semejanzas textuales aducidas, cabe pensar que la copla que estudiamos la compuso Ya'acob Yoná. Se nos plantea, sin embargo, la objeción de que, como también hemos dicho en el caso de Sa'adí Haleví, tampoco solía Yoná abordar en sus textos noticieros temas ajenos a la ciudad en donde vivía ${ }^{114}$. Pero, según los datos expuestos, parece evidente que hay que descartar la ciudad de Salónica como lugar del fuego, atribución que sólo viene sustentada por las explicaciones de las informantes de A y de C, las cuales, como he mencionado arriba, no eran naturales de dicha ciudad, sino de Rodas, lo que puede justificar su despiste.

Y además y para no dejar ningún cabo suelto de esta intrincada madeja, no puedo obviar la cierta sombra que se cierne sobre la

a pensar en una de dos: o que se trata de la misma cifra pero expresada en moneda de diferente valor; o que Yoná aprovechó una estrofa que ya había escrito antes, sin importarle demasiado la precisión monetaria. A título de curiosidad digamos que según indica Galante, en Histoire des Juifs d'Istanbul, vol. II pág. 139, el sultán Abdul Aziz donó 1.500 libras turcas para los damnificados del incendio que el 7 de agosto de 1872 asoló un barrio de Constantinopla. Parece, pues, como si los sultanes para ayuda de las víctimas de desastres más o menos naturales tuvieran previsto un presupuesto que oscilara entre 1.000 a 5.000 libras, según la magnitud de los mismos o según su generosidad del momento.

${ }^{114}$ Incluso en dos de las ocasiones en que tenemos constancia de que Yoná no estaba en Salónica, escribe sobre sucesos allí ocurridos. Así en 1903, estando en Sofía, publicó allí su librito titulado Cantes muevos por los teretemblos, con dos coplas sobre el terremoto sucedido en Salónica el 5 de julio de 1902 (BAECS 183); dicha copla la han publicado ATTIAS, «Yoná», núm. v (págs. 193-196), quien se ocupa además (pág. 160) del terremoto y de sus consecuencias; y yo misma en Coplas sefardies: Primera selección, Introducción de Iacob M. HASSÁN (Córdoba 1988) págs. 115-121; vid. también su traducción al hebreo en REFAEL, «Yoná», págs. 114117. Y en 1907, durante un viaje que realizó a Egipto, donde permaneció siete meses, publicó en El Cairo su Complas nuevas del felec y Sala de pasatiempo (BAECS 189), librito en el que, entre otras, incluye la copla que titulamos Robo en el puerto de Salónica (BAECS 189a), sobre un curioso acontecimiento sucedido en esa ciudad hacia 1905; publico esta copla en Entre dos fuegos, Cap. 7 núm. 38; vid. también REFAEL, «Yoná», pág. 106 y nota 29. Sobre el viaje de Yoná a Egipto vid. el apartado «La historia de mi viaje de Alexandría y Cairo (1907)», de Béatrice BÄNZIGER (págs. 57-68), en la publicación miscelánea Beatrice SCHMID (dir.), «Sala de pasatiempo»: Textos judeoespañoles de Salónica impresos entre 1896 y 1916 (Basel 2003 = Acta Romanica Basiliensa 14). 
autoría propuesta al tener en cuenta lo que ya he mencionado: que el coplero Yoná copiaba, y que, por tanto, a la hora de escribir las estrofas aducidas bien pudo valerse del texto de algún poeta de Constantinopla dedicado al incendio de 1883.

Por lo que tiene de gran interés en sí misma y también en cuanto a mostrar la relación de Ya'acob Yoná con la ciudad de Constantinopla, reproduzco aquí la curiosa noticia que me remite Dov Cohen, la cual apareció publicada en el periódico El Tiempo de Constantinopla (16 iyar 5636 [= 10 mayo 1876]):

Mešalem ra'á tahat tobá ['El que paga mal en lugar de bien'].Mientres un año entero que acabó el Pésah que venimos de pasar, nośotros tuvimos por obrador-mesader un cierto Ya'acob Yoná, morador de Salonic, que nos hićieron traer a nuestro servicio y que estaba sin ocupación. Todo este tiempo ganó más de 600 gru' al mes con nos, entre paga y hechos de afuera ${ }^{115}$; y agora Pésah, que se quis̀o ir a Salonic, avanzaba ande nos 150 gru' sólo ${ }^{116}$, que se los debíamos pagar pasando pocos días. Mientres este interval, nos viene una letra de Salonic dándomos informaciones por un sospecho que teníamos sobre unos libros que nos mancaban y nos aseguró cómo dito mesader nos llevó libros y los vendió. Por lo cual, en aribando a Custán, se le fue dicho que, si no mos tornaba los libros que nos mancaba o si no mos probaba que no era verdad las informaciones que recibimos, no podíamos darle los 150 grušes que quería.

En paga de lo que ganó con nos y que no podía ganar en ningún lugar, él cometió una negra hecha por vengarse. Día de alhad de mañana, nuestros laboradores viniendo por laborar topan los caracteres para la gaćeta machucados. Demandando al capiĝ́í del han, nos diće que día de šabat, no estando el hanĝí, Ya 'acob Yoná tomó diretamente la llave de la estamparía y, después de algún tiempo, salió. Agora no queda más safec que esta hecha no fue cometida de otro más que de Ya'acob Yoná, tanto que más que este miserable está desparecido de nuestra civdad de este mismo día.

\footnotetext{
${ }^{115}$ Es decir, que además de la paga fija, cobraba otros encargos que le hacían clientes ajenos.

${ }^{116}$ Es decir, le quedaban por cobrar sólo 150 grušes.
} 
Nośotros aseñalamos este hecho, en rogandando [sic] a la comunitá de Salonic que mire de apañar a Ya'acob Yoná (siendo estamos seguros que se fue a Salonic); y, si non la comunitá de Salonic estará segura ${ }^{117}$ del paso que estamos contando, mirará de castigar a esta aborecida persona. De resto, la otoritá propria ya va haćer sus buenas búšquedas por castigar a Ya'acob Yoná según lo merece.

Detrás de esto, nuestros leedores no tienen demenester de saber por qué no salió nuestro folio de lunes y, hasta que nos procuremos los caracteres que encomendimos para nuestro menester, nuestra gaćeta saldrá por pocos días a medio folio.

Gracias a esta noticia, supongo que redactada por el ciertamente exasperado David Fresco, director de El Tiempo, averiguamos que nuestro coplero andaba sin empleo a mediados de los 70 y que permaneció trabajando en la imprenta de Fresco entre las primaveras de 1875 y 1876 para luego volver a Salónica. ¿Fueron sus nostalgias constantinopolitanas las que le impulsaron a escribir una copla sobre el incendio ocurrido en 1883 en la ciudad?

Para terminar y como resumen quiero decir que hoy por hoy me inclino a pensar que la copla que he estudiado la escribiera el propio Yoná. De ser así, conviene señalar que, por lo que hasta el presente conocemos, sería ésta la copla más antigua de las compuestas y publicadas por Yoná.

Pero todo lo dicho queda a expensas, claro está -y a ello humildemente me resigno- de lo siguiente: (a) en cuanto al lugar, de que alguna vez obtengamos otros datos históricos que desmientan mi actual opinión, demostrando que ese año sí hubo en Salónica un gran incendio ${ }^{118}$; y (b) en cuanto a la autoría, del resultado que en el

117 La frase no me queda clara; la he puntuado como si quisiera decir «y a no ser que la comunidad de Salónica no esté segura de lo que contamos».

118 Para no tirar del todo la toalla sobre un incendio en Salónica en 5644, me acojo a las palabras de Sa'adí Haleví (en «Mis memorias», cap. 18, cito por EMMANUEL, Guedolé, pág. 13), según las cuales en sus 80 años de vida (1820-1900) conoció en Salónica más de cien incendios graves, de muchos de los cuales no nos ha llegado noticia. 
futuro nos ofrezca el pendiente estudio analítico y comparativo de los textos que conocemos -tanto de los noticieros, en general, como de los incendios, en particular-, estudio en el que, quizás, se pueda rastrear otra pluma diferente de la de Yoná. A todo ello hay que añadir (c) que en algún momento alguien -pienso, por ejemplo, Dov Cohen o Avner Perez- nos sorprenda con la magnífica noticia de haber encontrado una edición que contenga la copla que nos ocupa, lo que nos sacaría de muchas dudas.

Y que se publicó lo sabemos por las palabras con las que hace preceder su versión la informante de $\mathrm{C}$, natural de Rodas (recordemos que de allí proceden también las de A y D), palabras que vienen también a explicar por qué la copla tuvo una especial difusión en la isla. Esto es lo que oímos en la grabación de Armistead y Silverman, frases que, al menos en nuestra copia, se inician exabrupto:

... quimados y cantaban unas canciones para que... para que les dieran, venían a las puertas, cantaban y compraban los libricos estos; qué me s'hiźo no sé». [Armistead pregunta:] «¿Usted tenía esos libros?» [y la informante contesta:] «[Yo] tenía un librico d'estos, que uno s'amanćiaba de sentir los vierbos qu'estos mancebos cantaban...; enteros quemados, enteros. [Armistead pregunta:] «¿De dónde venían?, ¿de Salonic?» [y la informante contesta:] «Sí, del fuego de Selanic».

De estas algo descompuestas frases se deduce que por Rodas aparecieron jóvenes venidos, en el decir de la informante, de Salónica, vendiendo unos libritos que contenían unas coplas sobre un incendio; las gentes, apiadándose de ellos, se los compraban y les daban dinero. Tales libritos serían ejemplares de una publicación hasta ahora desgraciadamente perdida que vería la luz hacia 1883 y que contendría completa la copla que la tradición oral nos ha conservado manca ${ }^{119}$.

\footnotetext{
${ }^{119}$ El presente artículo se ha elaborado dentro del Proyecto de investigación «Sefarad Siglo XXI (2005-2007): Edición y estudio filológico de textos sefardíes» (núm. BFF 2001-0239 de la PGC, DGI). Quiero agradecer a cuantos me han ayudado en su elaboración, y muy especialmente a Dov Cohen, por sus inapreciables materiales y precisiones; y a I. M. Hassán, por sus siempre agudas observaciones. Agradezco
} 


\section{GLOSARIO}

abot: 'padres; patriarcas' (hb. אבות).- alhad: 'domingo'.- amanćiarse: 'apiadarse, compadecerse'.- andar: vid. nota 77.- apropiar: 'destinar, asignar'.- ariftar: 'reprender'.- 'asacá: vid. nota 11.- atentar: vid. nota 66.- ba'avonot: 'por desgracia' (hb. בעוונות, lit. 'por los pecados').- bacal: 'tendero' (tc. bakkal).- baraná: 'clamor, tumulto; pelea' (cfr. tc. bağr 'gritar, clamar').- Caimacán: 'en funciones, interino' (tc. kaimmakam, kaymakam).- capiôí: 'portero' (tc. kapıcı).- carar: 'medida, grado' (tc. karar 'cantidad, cuenta').- chadires: 'tiendas de campaña' (pl. de tc. çadır).- čharší: 'mercado' (tc. çarşı).- corbanot: 'sacrificios, ofrendas' (hb. קורבנות).-- cunbaraĝís: 'artilleros, artificieros' (pl. de tc. kumbaracı).curutú: a — 'en abundancia, muchos' (cfr. tc. götürü 'al por mayor').Custán: 'Constantinopla'.- deśgonbrar: vid. nota 26.- desmaźalado: 'desgraciado, sin maźal' (hb. מזל, 'suerte, fortuna').- despenar: 'aliviar las penas'.- efendi: 'señor, caballero', título honorífico (tc. efendi).- Elía: vid. nota 28.- elohut: 'divinidad' (hb. אלהות elahut).- emuná: 'fe, confianza' (hb. אמונה).- enteśados, intiśados: 'tiesos, helados'; vid. también nota 62.esconbranza: haćer — vid. nota 13.- esnaf, eśnaf, eśnav: 'comerciante, persona de clase media; burguesía' (tc. esnaf 'perteneciente a un gremio artesanal').- estamparía: 'imprenta'.- fado: 'hado'.- galut: 'exilio, diáspora' (hb. גלות).- geveźlí: 'de madera de nogal' (tc. ceviz 'nogal').gilalí: 'brillante, relustroso' (tc. cilâlı).- goel: 'redentor' (hb. גואל).- grušes (abrev. gru'): 'piastras' (pl. de tc. guruş, kuruş).- guebir, guibir: 'rico; persona importante' (hb. גביר).- guemará: 'folleto' (hb.-arm. גמרא 'tratado del Talmud').-- gueulá: 'redención' (גאלולה).- gueźerá: 'sentencia (desfavorable), condena' (hb. גזירה).- haftoná: 'paliza, apaleamiento' (dícese que de hb. חבטה 'golpe').- han: 'edificio' (tc. han).- hanĝí: 'vigilante, portero' (tc. hanc1).- harab: 'el rabí' (hb. הרב).- harat 'olam: vid. nota 45.- harbados: 'golpeados'.- haŝerot: 'patios' (hb. חצרות).hatir: 'favor, consideración' (tc. hatır); haćer — 'hacer un favor'.hayom: 'hoy' (hb. היום).- ihsán: haćer —_donar' (cfr. tc. ihsan et-). iradé: 'decreto imperial' (tc. irade).- Iyob: 'Job' (hb. איוב).- Iźmir: 'Esmirna'.- kislev: tercer mes del calendario judío; tiene 30 ó 29 días y su comienzo oscila entre el 5 de noviembre y el 3 de diciembre (hb. כסליו).Kubarhané, Kumbarhané: vid. nota 93.- ma: 'pero’ (tc. ama).- mašíah:

asimismo a las bibliotecas y particulares que me han permitido el uso de sus fondos: Ben Zvi Institute (Jerusalén), Fonoteca de la Universidad Hebrea de Jerusalén, Proyekto Folklore de la Radio-Televisión de Israel, y Samuel G. Armistead. 
'ungido, mesías' (hb. (משיח).- maŝlíah: ser —_ 'lograr, conseguir' (hb. (מצליח 'el que logra').- mavís: vid. nota 76.- medianos: días de media fiesta, entre el primer y último día de Pésah y de Sukot.- mélej: 'rey' (hb. מלך).-- mender: 'colchón' (tc. minder).-- mesader: 'tipógrafo' (hb. מסדר).mesta: vid. nota 20.- meźonot: 'alimentos, vituallas' (hb. מזונות).meźuźá, miźuźá: estuche alargado que contiene un pergamino enrrollado en el que están escritos dos pasajes alusivos de la oración de la Šemá ' (Deut 6.4-9 y 11.13-21) y que es preceptivo fijar en las puertas, en la parte superior de la jamba derecha (hb. מזוזה).- miŝvot: 'buenas obras' (hb. מצוות 'preceptos').- mobillas: 'mobiliario'.- mo'ed: 'fiesta, conmemoración' (hb. מועד).- mulques: 'propiedades' (pl. de tc. muilk).niftar: ser - 'morirse' (hb. נפטר 'muerto, murió').- 'od: 'aún, todavía' (hb. עוד).-- paderes: vid. nota 10.- peče: 'pescado'.- Pésah: 'Pascua' (hb. (פסח).- pico: cierta medida de longitud.- potín: 'botín' (tc. potin, botin).quehilot: 'sinagogas' ( $\mathrm{hb}$. קהילות).- quiesatlic: 'carestía, crisis' (tc. kesatlk).- quišlás: 'barracones' (pl. de tc. ksşla).- quitar: vid. nota 7.rahamán: 'misericordioso' (hb. רחמן).- rahatlic: 'bienestar, tranquilidad' (tc. rahatlık).- rebellos: 'desobediencias, actos de rebeldía'.- rehmidor: 'redentor'.- riźa: 'pañuelo' (tc. rida 'echarpe').- Roš hašaná: 'Primero de año' (hb. ראש השנה): vid. nota 5.- rúah: 'aliento' (hb. רברוח).- sáarar: 'angustia, aflicción' (hb. צער).-- šabat: 'sábado' (hb. שבת (hadic: 'justo'

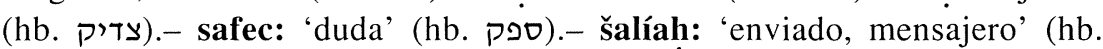

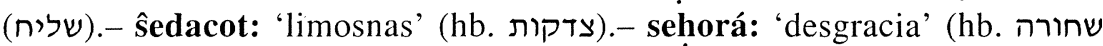
'negra').- sin'at hinam: 'odio gratuito' (hb. שנאת חנם, lit. 'odio de balde').- ta'aniyot: 'ayunos' (hb. תעניות).- tefilot: 'oraciones' (hb. תפילות).- tešubá: hacer - _arrepentirse' (hb. תשובה arrepentimiento').tiralí: vid. nota 77.- trabar: — vida 'vivir, llevar (una) vida'; _- males 'sufrir, soportar males'; vid. también nota 16.- umá (pl. umot): 'nación, pueblo' (hb. אומות ,אומה).- huźur: 'paz, reposo, tranquilidad' (tc. huzur).vista: de — 'enseguida, inmediatamente'.- volar: 'morir'.- yašar: 'justo, recto' (hb. ישר).- yaveres: 'asistentes, ayudas de campo' (pl. de tc. yaver).Yisrael: 'Israel; todos los judíos' (hb. ישראל).- źabit: 'policía, gendarmería encargada principalmente de mantener el orden' (tc. zâbita, zâbit, zaptiye).źeflenearse: 'burlarse, mofarse' (cfr. tc. zevklen-).- źejut: 'mérito, merecimiento' (hb. זכות).- źimán: vid. nota 58.- źojim: ser -_ 'merecer' (hb. זוכים 'merecedores').- źorbalís: vid. nota 12. 


\section{RESUMEN}

En el presente artículo se editan y estudian dos coplas sefardíes que nos han llegado anónimas: las denominadas El incendio de Salónica de 1839, procedente de un manuscrito de Belgrado (1861); y El incendio de Constantinopla de 1883, conservada en cuatro versiones orales. En el estudio la autora determina el lugar y fecha de los incendios, así como sus posibles autorías -Sa'adí Haleví y Ya 'acob Yoná, respectivamente-; de estar en lo cierto, se trataría de las coplas más antiguas que hoy por hoy conocemos de esos dos famosos copleros salonicenses.

Palabras Clave: Coplas sefardíes, Sacadí Haleví, Yacacob Yoná, Salónica, Constantinopla.

\section{SUMMARY}

The present article presents the edition and study of two anonymous Sephardic coplas, namely the so-called El incendio de Salónica de 1839, preserved in a manuscript from Belgrade (1861), and El incendio de Constantinopla de 1883, known from four oral versions. The author suggests the exact place and date of the fires, as well as the authorship of both compositions, namely Sa'adi Halevi and Ya'aqob Yonah, respectively. If the interpretation proves correct, these coplas would constitute the oldest extant compositions by the two famous Saloniki copleros.

Keywords: Sephardic coplas, Sa'adi Halevi, Yáacob Yonah, Salonika, Constantinople. 